\title{
On the dynamics of Atlantic Water circulation in the Arctic Ocean
}

\author{
M. Karcher, ${ }^{1,2}$ F. Kauker, ${ }^{1,2}$ R. Gerdes, ${ }^{1}$ E. Hunke, ${ }^{3}$ and J. Zhang ${ }^{4}$ \\ Received 10 April 2006; revised 23 October 2006; accepted 22 February 2007; published 26 April 2007.
}

[1] We use a subset of models from the coordinated experiment of the Arctic Ocean Model Intercomparison Project (AOMIP) to analyze differences in intensity and sense of rotation of Atlantic Water circulation. We focus on the interpretation of the potential vorticity (PV) balance. Results differ drastically for the Eurasian and the Amerasian Basins of the Arctic Ocean. We find indications that in the Eurasian Basin the lateral net flux of PV is a significant factor for the determination of the sense of rotation of Atlantic Water circulation on timescales beyond pentades. The main source of high PV causing cyclonic circulation in the Eurasian Basin is the Barents Sea, where the seasonal cycle of surface buoyancy fluxes forms stratified water that leaves the shelf and feeds the Atlantic Water Layer (AWL) in the Arctic Basins. However, in the Amerasian Basin vertical PV fluxes are the more important factor. These are closely related to wind field changes. We find an intense response of the AWL flow to wind forcing, approximated by the sea level pressure difference between the Bering Sea and the central Canadian Basin, which describes about half the variance of AWL flow of the Amerasian Basin. An experiment driven with a repeated atmospheric climatology exhibits an extreme case where a permanent high pressure system over the Beaufort Sea dominates the circulation in the Amerasian Basin, demonstrating the potential of the Beaufort Gyre to adjust in such a way as to suppress a cyclonic AWL flow in the Amerasian Basin. In more realistic cases the Beaufort Gyre still modulates the Amerasian Basin AWL circulation significantly.

Citation: Karcher, M., F. Kauker, R. Gerdes, E. Hunke, and J. Zhang (2007), On the dynamics of Atlantic Water circulation in the Arctic Ocean, J. Geophys. Res., 112, C04S02, doi:10.1029/2006JC003630.

\section{Introduction}

[2] The Arctic Ocean Model Intercomparison Project (AOMIP) endeavours to understand differences in model performance by comparing model simulations with data and with each other [Proshutinsky et al., 2005] (http://fish.cims. nyu.edu/project_aomip/overview.html). AOMIP's objective is to develop suggestions for future Arctic modeling on global or regional climate scales, and to contribute to an enhanced understanding of the physics of the Arctic Ocean. For this purpose a protocol has been developed for a coordinated experiment in which topographic and hydrographic initial conditions, atmospheric forcing and surface flux bulk formulae are fixed. The variety of models is large, ranging from regional to global domain, different vertical coordinates such as Z-, sigma-, or isopycnal coordinates, and free surface or rigid lid assumptions at the ocean's upper surface. Previous intercomparison studies from AOMIP have focussed on stream function, heat and fresh

\footnotetext{
${ }^{1}$ Alfred Wegener Institute for Polar and Marine Research, Bremerhaven, Germany.

${ }^{2}$ O.A.Sys - Ocean Atmosphere Systems, Hamburg, Germany.

${ }^{3}$ Los Alamos National Laboratory, Los Alamos, New Mexico, U.S.A.

${ }^{4}$ Polar Science Center, Applied Physics Laboratory, University of Washington, Seattle, Washington, U.S.A.

Copyright 2007 by the American Geophysical Union. 0148-0227/07/2006JC003630\$09.00
}

water content [Steiner et al., 2004], and energy diagnostics [Uotila et al., 2005].

[3] In this investigation we analyze the circulation of the Atlantic Water Layer (AWL) of the Arctic Ocean. It is fed by an inflow of water of Atlantic origin via the Fram Strait and the Barents Sea (Figure 1). In the central Arctic Ocean the AWL forms a layer of maximum temperatures and typically occupies a depth range of about $200 \mathrm{~m}$ to $1000 \mathrm{~m}$, separated from the fresh surface layer by a strong halocline. It forms cyclonic gyres in the Eurasian Basin and the western ("Amerasian") basins, namely the Makarov and the Canadian Basin [Aagaard, 1989; Rudels et al., 1994]. A second source of Atlantic Layer water is the Barents Sea. Water of Atlantic origin enters the Barents Sea between Norway and Svalbard and is subjected to large buoyancy fluxes due to heat loss and ice freeze/melt. The dense water formed in the Barents Sea leaves the shelf mainly via the St. Anna Trough, a deep trench which connects the shelf with the Eurasian Basin. These water masses feed into the different density layers of the Arctic basins, the bulk draining into the thick AWL [Rudels et al., 1994; Schauer et al., 1997]. On leaving the Arctic proper after recirculating in the different basins for a period of $\mathrm{O}(20$ years) [Smethie et al., 2000; Schlosser et al., 1995; Karcher et al., 2003a, 2003b] the middepth Atlantic Water exits the Arctic Ocean via Fram Strait and forms an important source water mass for the overflow waters of the Greenland-Scotland Ridge. 


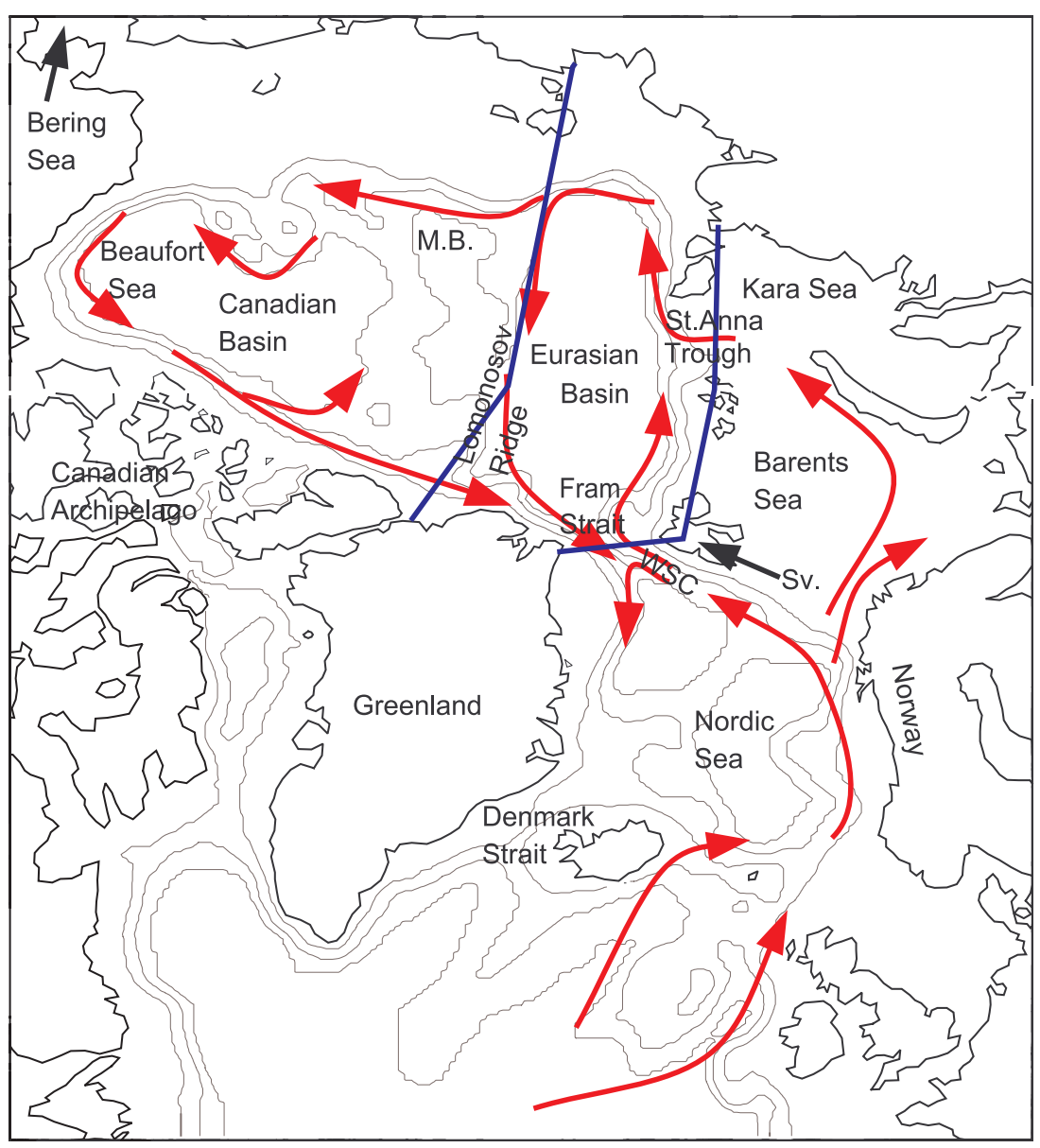

Figure 1. Topography of the Arctic Ocean, the Nordic Seas and the northern North Atlantic Ocean. Arrows indicate the cyclonic movement of Atlantic water. In the Arctic Ocean these flows circulate below the surface in the Atlantic Water Layer (AWL), following Rudels et al. [1994]. Blue lines show the boundaries separating 'Amerasian' and 'Eurasian' basins used for analysis in the text. Geographical names used in the text are given. M.B., Makarov Basin; Sv, Svalbard.

These feed into the lower limb of the meridional overturning circulation [Mauritzen, 1996; Rudels et al., 1999].

[4] Sound observational evidence exists for cyclonic motion of the AWL rim currents in the 1980s and 1990s stemming from hydrographic [Rudels et al., 1994; Swift et al., 1996] and tracer data [Smethie et al., 2000; Smith et al., 1999]. However, the realization of Arctic Ocean circulation by different modeling exercises exhibits differences in the intensity, pathways and even direction of Atlantic Water circulation [e.g., Häkkinen and Mellor, 1992; Holland et al., 1996; Gerdes and Schauer, 1997; Nazarenko et al., 1998; Karcher and Oberhuber, 2002; Karcher et al., 2003a, 2003b]. Are these differences caused by different model formulations, atmospheric forcing fields, applied open boundary conditions, simulation domains or spatial resolution? As it turns out, even the set of AOMIP simulations from the coordinated experiment exhibit strong differences.

[5] Questions arise: what are the driving forces for the sense of flow in reality and in the model experiments? What is the role of the inflow conditions in contrast to the local wind fields, or the history of the inflow in terms of density contrasts between the boundary current and interior?
[6] The paper will be separated into two parts. The first part consists of an analysis of Atlantic layer potential vorticity in a subset of the AOMIP models, discussing the influence of lateral potential vorticity fluxes on the circulation. Two further experiments are analyzed in detail in the second part to distinguish the influences of the lateral potential vorticity inflows and the wind fields on circulation of AWL in the different Arctic basins. We end with conclusions from these results and implications for future work.

\section{Coordinated AOMIP Experiments}

\subsection{Models}

[7] From the set of coupled ice-ocean models that have participated in the AOMIP coordinated experiment (http:// fish.cims.nyu.edu/project_aomip/experiments/coordinated analysis/overview.html) [Uotila et al., 2005], we choose three which differ in their representation of Atlantic Water flow: AWI, a version of regional NAOSIM (the North Atlantic/Arctic Ocean Sea Ice Model) developed at the Alfred Wegener Institute for Polar and Marine Research (AWI) [e.g., Gerdes et al., 2003]; LANL, a global version of the POP-CICE model developed at the Los Alamos 
National Laboratory [Hunke and Holland, 2007]; and UW, a POP-based regional model of the Applied Physics Laboratory, University of Washington [Zhang and Steele, 2007]. The regional domain models, AWI and UW, have southern boundaries at $50^{\circ} \mathrm{N}$ and $65^{\circ} \mathrm{N}$, respectively. The horizontal resolution in the Arctic domain is $\sim 28 \mathrm{~km}$ for AWI, $\sim 20 \mathrm{~km}$ for LANL and $\sim 40 \mathrm{~km}$ for the UW model. The AOMIP protocol specifies use of the IBCAO topography, and the PHC climatology [Steele et al., 2001] for the initial conditions and for restoring sea surface salinity for the first 10 years. The switch to nonrestoring from year 11 onwards results in a strong drift of model hydrography for the AOMIP models shown here. The atmospheric forcing data are wind stress calculated from NCEP SLP data via bulk formulae, NCEP temperatures, humidity, precipitation climatology from Serreze (personal communication), and cloud fraction from OMIP climatology [Röske, 2001]. For global models, high latitude winds are blended south of $60-65^{\circ} \mathrm{N}$ with NCEP reanalysis data in the rest of the domain.

[8] In contrast to the subset of AOMIP models used here, some of the models participating in the AOMIP study use an explicit parameterization of subgrid-scale eddy-topography interaction in the form used in Nazarenko et al. [1998]. This parameterization acts as a source of PV and thus has a significant influence on the PV balance of the flow. This should be taken into account for the interpretation of those results.

\subsection{Atlantic Water Circulation at $\mathbf{3 0 0} \mathbf{m}$ Depth}

[9] At the beginning of the coordinated experiment the sense of rotation for the AWL flow is strongly influenced by the initial density field based on the PHC climatology. As a consequence of the smoothed hydrographic fields in the PHC climatology, density gradients in the Arctic boundary currents are weak, especially in the Canadian Basin. Ice and surface ocean flows are driven by the anticyclonic wind and surface density fields, establishing the Beaufort Gyre in the Canadian Basin. Weak density gradients in the AWL are not able to counteract the anticyclonic surface flows at this early stage and thus the in situ velocities in the boundary currents of the Amerasian Basin are anticyclonic in all three experiments. Further development, however, is very different among the experiments. For a view on a larger set of AOMIP coordinated experiment results, see the paper of Holloway et al. [2007].

[10] In the AWI experiment, the Eurasian Basin is dominated by cyclonic flow almost from the start. After 1953 the AWL boundary currents in the other Basins become cyclonic, too, starting with the Makarov Basin, followed by the Beaufort Sea and finally the northern Canadian and Greenland slopes (Figure 2). The AWL flow in the AWI model stays cyclonic for most of the rest of the experiment, with some variability in the intensity and location of the circulation, and period of anticyclonic motion in the Canadian Basin in the 1970s.

[11] In the LANL simulation, the AWL flow in the boundary currents becomes cyclonic in the Eurasian Basin after 1953 but stays anticyclonic in the entire Amerasian Basin until the late 1960s. The successive switch of the boundary current direction in the basins, starting with the Eurasian, via the Makarov Basin, the Beaufort Gyre and the Canadian slope, happens in a similar fashion as in the AWI model, but at a later stage in the experiment.
[12] In the UW simulation the Eurasian Basin is dominated by cyclonic flow. The boundary currents of the Canadian Basin switch to cyclonic flow in the 1950s while the flow in the interior and the connecting flows between the basins are very variable in location and direction. Even though the dominant motion in the Canadian Basin is cyclonic, the Makarov Basin remains anticyclonic for the entire experiment.

\section{Potential Vorticity Analysis}

[13] In the following section we analyse the potential vorticity (PV) of the AWL in the attempt to better understand the driving forces for the basin-scale flow. This analysis is motivated by a recent investigation of Yang [2005], who used a highly idealized, single-layer, barotropic model of the Arctic Ocean to study the dependence of middepth Arctic flow patterns on the net lateral PV flux. His study is based on the theoretical consideration that for a semienclosed basin like the Arctic Ocean, the PV integral over the entire basin yields a balance of net lateral PV inflow and dissipation of PV along boundaries in steady state. Following Yang and Price [2000] in this concept mass fluxes across interfaces in the interior have no net contribution to the PV integral over the basin. The following equation shows the area integral of the steady state PV equation in the form of a line integral along the side boundary $\mathrm{C}$ according to Yang [2005, equation (4)], in which $\vec{U}$ is the horizontal transport velocity vector, $\vec{n}$ the unit vector perpendicular to the lateral contour $\mathrm{C}, \zeta$ is the relative vorticity, $\mathrm{D}$ is the PV dissipation term, $f$ is the planetary vorticity, and $H$ is the total depth.

$$
\oint_{C}(\vec{U} \cdot \vec{n}) \frac{(f+\zeta)}{H} d s=\iint_{A} D d x d y
$$

[14] Yang [2005] found that cyclonic rotation could be switched to anticyclonic by changing the net PV flux across the open boundaries from positive to negative (in his example by changing topography in Fram Strait); balancing the net inflow of PV by dissipation in the interior implies changes of flow patterns. Here we examine if this simple balance is likely to hold in the case of full-fledged, baroclinic GCMs and whether the analysis of the PV balance can aid in the interpretation of the AWL flow. We first inspect our subset of AOMIP models and then analyze two experiments performed with NAOSIM. In Yang [2005] the thickness of the only layer was governed entirely by the topography. This contrasts with the present analysis, in which we choose potential density interfaces appropriate for representing the upper and lower AWL boundaries in the experiments. This implies that a major contribution to the PV will come from changes in the layer thickness. In contrast to the steady state situation analyzed by Yang [2005] we investigate time dependent experiments. Starting from the conservation of PV, the tendency of PV and a term representing PV flux in the vertical direction remain as part of the equation.

$$
\begin{aligned}
& \iint_{A} \frac{\delta}{\delta t} P V d x d y+\iint_{A} \frac{\delta}{\delta z}(w P V) d x d y+\oint_{C}(\vec{u} \cdot \vec{n}) P V d s \\
& =\iint_{A} \frac{D}{h} d x d y
\end{aligned}
$$



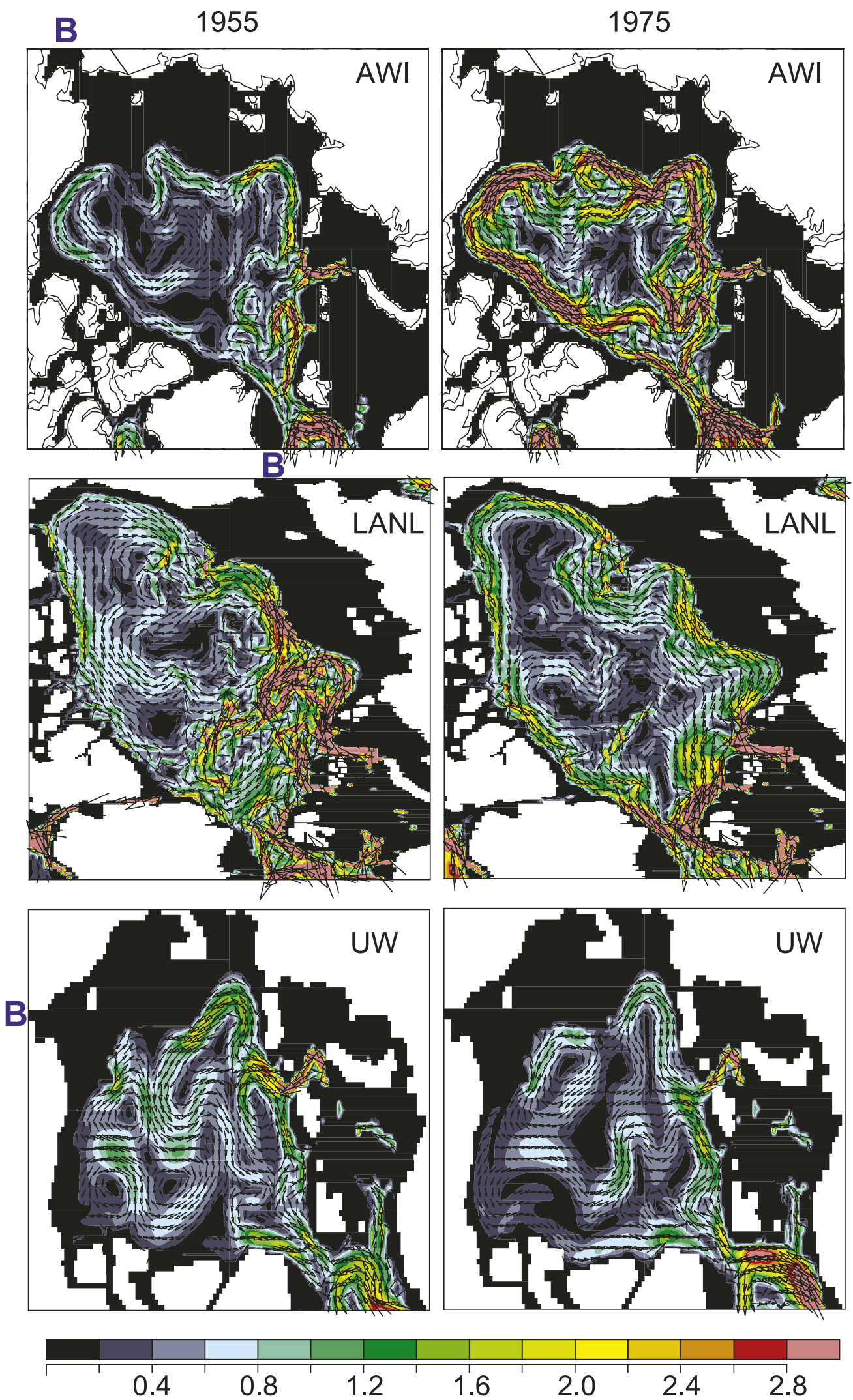

Figure 2. Velocities in the core of the AWL (at about $300 \mathrm{~m}$ ) for a subset of the AOMIP models. (left) Yearly mean flow patterns in 1955; (right) for 1975 . The color code gives velocity in $\mathrm{cm} / \mathrm{s}$. Not every velocity vector is shown. The blue 'B' points out the location of the Bering Strait in each of the model grids for convenience of orientation. 
a)

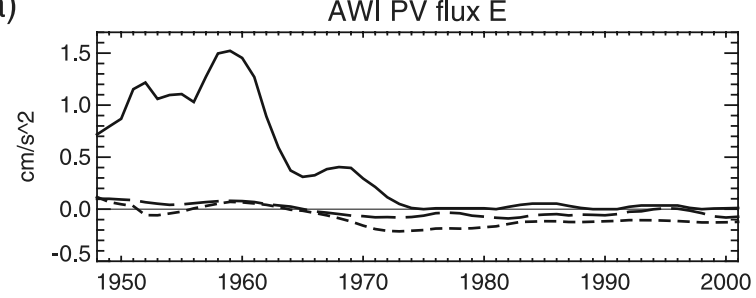

b)

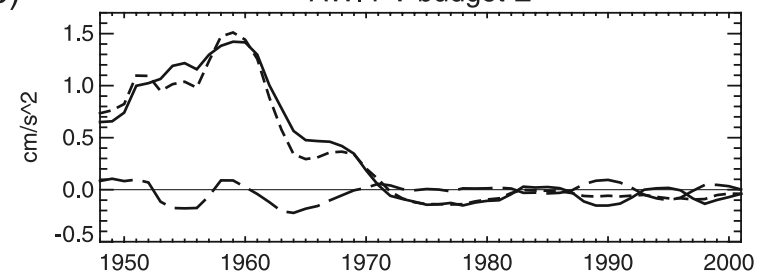

c)

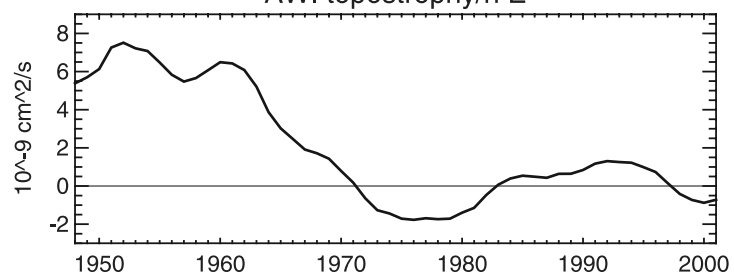

d)

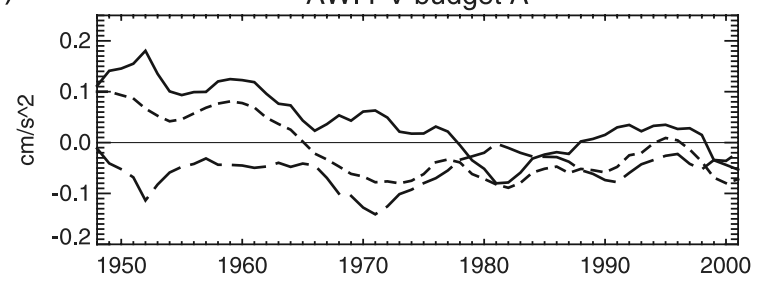

e)

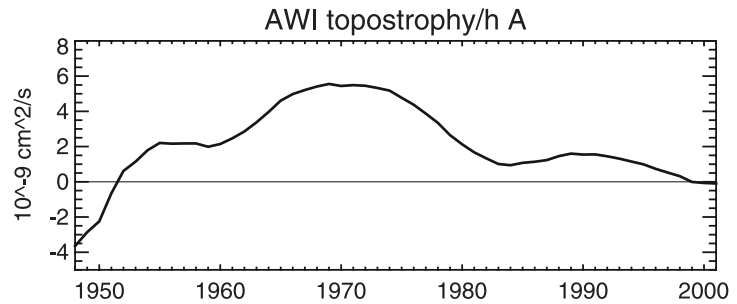

Figure 3. Calculated contributions to the PV budget for the AWI model experiment, as areal integral for the density interval $\sigma=27.8-28.0$ in the (left) Eurasian Basin (E), and the (right) Amerasian Basin (A). (a) Lateral flux of PV into E through Fram Strait (short dashed), St. Anna Trough (long dashed), and the total (solid), (b) PV budget (solid) in E as calculated from total net PV inflow (short dashed) minus the tendency of PV (long dashed), (c) basin mean topostrophy/h in E. (d) PV budget (solid) in A as calculated from total net PV inflow across the Lomonosov Ridge (short dashed) minus the tendency of PV (long dashed), and (e) basin mean topostrophy/h in A. The analysis is based on yearly mean values. The shown time series are filtered with a 3-year running mean.

with

$$
P V=\frac{f+\zeta}{h}
$$

where $\vec{n}$ is directed outwards, $\mathrm{h}$ is the layer thickness and $\mathrm{w}$ and $\vec{u}$ are the vertical and horizontal velocity components, respectively. Note that deviating from Yang [2005] here no additional vertical integration has been performed. An a posteriori calculation of the full PV balance for each of the models, including possible contributions from cross-interfacial processes, is not feasible for this study, since our analysis is based on monthly means. Instead, we concentrate on the relationship between lateral PV fluxes, temporal changes of PV content and behavior of the AWL flow. Because of the interface depths of the density intervals representing the AWL, the only open lateral boundaries allowing PV fluxes are Fram Strait and St. Anna Trough for the Eurasian Basin and the Lomonosov Ridge for the Amerasian Basin, respectively.

[15] We make use of layer mean "topostrophy" to characterize the large-scale sense of the boundary currents in the AWL. Topostrophy [Holloway et al., 2007] is a diagnostic that reduces the sense of the flow field to a scalar, capturing the dominant type of motion for a basin if calculated as a spatial integral. High positive topostrophy is equivalent to strong cyclonic flow along steep topography, with the shallow depths to the right:

$$
T=(\vec{u} \times \vec{\nabla} H) \cdot \vec{z}
$$

Here $\mathrm{H}$ is the bottom depth, while $\vec{z}$ denotes the unit vertical vector. With this definition of topostrophy cyclonic flow over steep topography has the largest positive value. This is where PV dissipation is expected to be strongest, too. Therefore we use topostrophy as a proxy for the dissipation of PV:

$$
\iint_{A} \frac{D}{h} d x d y \propto \iint_{A} \frac{T}{h} d x d y
$$

Since the behavior of the Eurasian Basin differs from the behavior of the Amerasian Basin, it is convenient and illustrative to perform a separate calculation of the topostrophy for the two basins. We follow the definition of 'Eurasian' and 'Amerasian' basins of Holloway et al. [2007] in which the basic separation line is the Lomonosov Ridge (Figure 1).

\subsection{PV Analysis of AOMIP Experiments}

[16] The analysis of PV and topostrophy for the AOMIP set of experiments covers the density interval $\sigma=27.8-$ 
a)

UW PV flux E

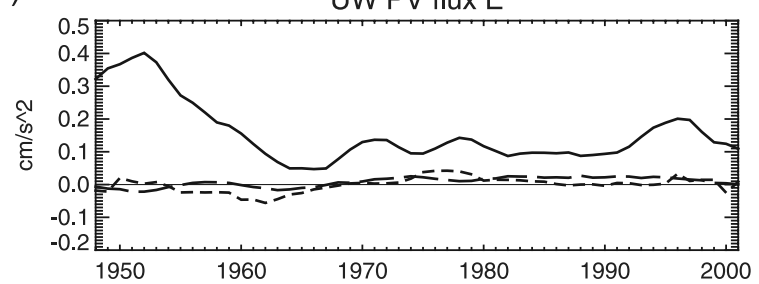

b)

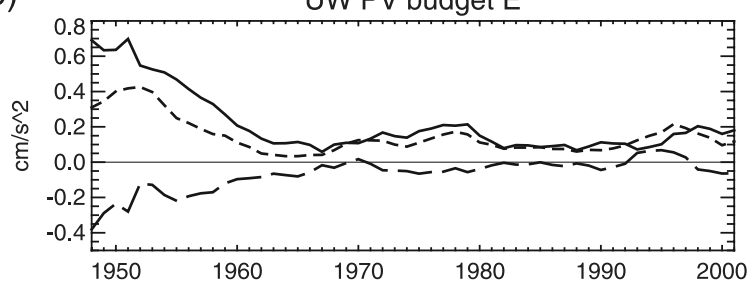

c)

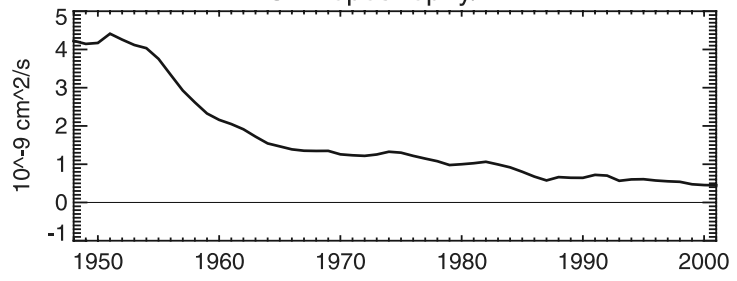

d)

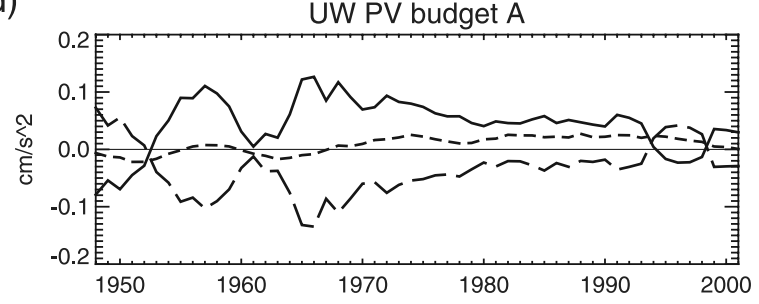

e)

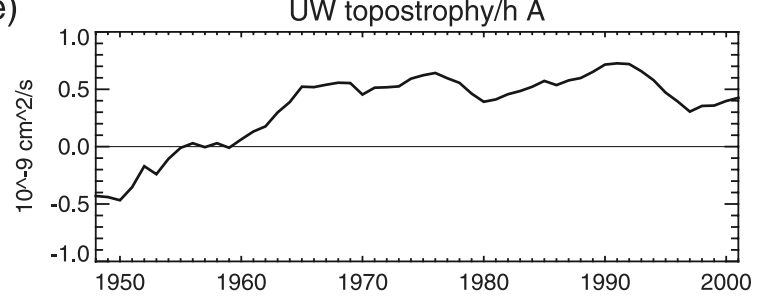

Figure 4. Calculated contributions to the PV budget for the UW model experiment, as areal integral for the density interval $\sigma=27.8-28.0$ in the (left) Eurasian Basin (E), and the (right) Amerasian Basin (A). (a) Lateral flux of PV into E through Fram Strait (short dashed), St. Anna Trough (long dashed), and the total (solid), (b) PV budget (solid) in E as calculated from total net PV inflow (short dashed) minus the tendency of PV (long dashed), (c) basin mean topostrophy/h in E. (d) PV budget (solid) in A as calculated from total net PV inflow across the Lomonosov Ridge (short dashed) minus the tendency of PV (long dashed), and (e) basin mean topostrophy/h in A. The analysis is based on yearly mean values. The shown time series are filtered with a 3-year running mean.

28.0, which captures the bulk of the AWL in the investigated AOMIP models. We calculate the spatial mean of $\mathrm{PV}$ tendency, lateral fluxes of PV and topostrophy/h between the depths of these density levels for the two subbasins separately. Where the lower interface reaches the bottom, the bottom depth is used as lower boundary of the density layer. To avoid problems with very thin AW layers, all grid points with an AW layer depth of less than $30 \mathrm{~m}$ have been omitted from the analysis. We name the difference of the two directly calculated terms lateral PV fluxes and PV tendency as 'PV budget'. If vertical fluxes of PV were small, the PV budget on the left hand side of equation (2) would have to be balanced by dissipation. The temporal evolution of the PV budget will be compared with the topostrophy over thickness $\mathrm{h}$.

[17] The dominant source of the net PV inflow into the Eurasian Basin of the AWI model is St. Anna Trough, where strongly stratified water from the Barents Sea enters the basin, while Fram Strait and the loss of PV across the Lomonosov Ridge into the Amerasian Basin provide small contributions only (Figure 3a). The PV tendency is small, too (Figure $3 b$ ). The PV budget is therefore controlled by the St. Anna Trough PV inflow. If the basic balance of PV inflow and dissipation in the basin [Yang, 2005] holds, we would expect a strong cyclonic flow during the first 2 decades. Indeed in the Eurasian Basin topostrophy/h is high for this period (Figure $3 \mathrm{c}$ ). Subsequently a sharp decrease of the net PV inflow to values around zero occurs, with the PV tendency being negligibly small. The topostrophy/h of the Eurasian Basin is significantly reduced, too. In the 1970s weak net outflow of PV goes along with negative topostrophy/h. Thus here a balance of lateral PV fluxes and dissipation seems reasonably well established.

[18] For the Amerasian Basin the situation is different. Lateral inflow of PV across the Lomonosov Ridge and PV tendency contribute to the budget with similar strength (Figure 3d). While during most of the experiment the topostrophy/h is positive (Figure 3e), its temporal development bears only weak resemblance with the PV budget. In other words, PV tendency, PV dissipation and lateral fluxes of PV are not the only players contributing significantly to the PV balance; vertical PV fluxes must also have an effect on the circulation of the Amerasian Basin.

[19] Also in the UW model the the input of PV through St. Anna Trough dominates the net PV inflow to the Eurasian Basin and is positive over the entire period (Figure 4a). During the first decade the tendency term contributes to the PV budget with similar order of magnitude as the lateral fluxes (Figure 4b). In the Eurasian Basin dissipation acts as to balance the PV budget, which can be inferred from the cyclonic boundary currents shown by positive topostrophy/h (Figure 4c). As in the AWI experiment the long term temporal development of the topostrophy/h and the PV budget are very similar. 
a)

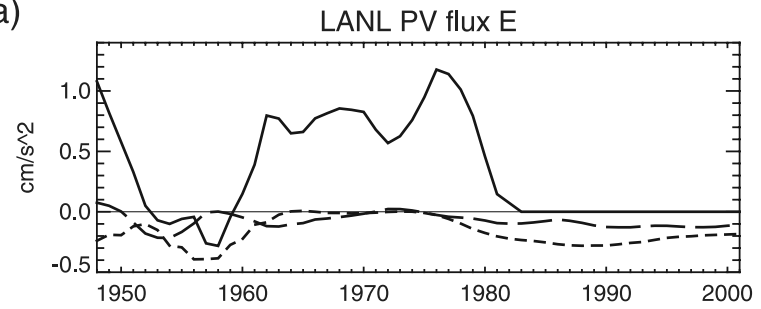

b)

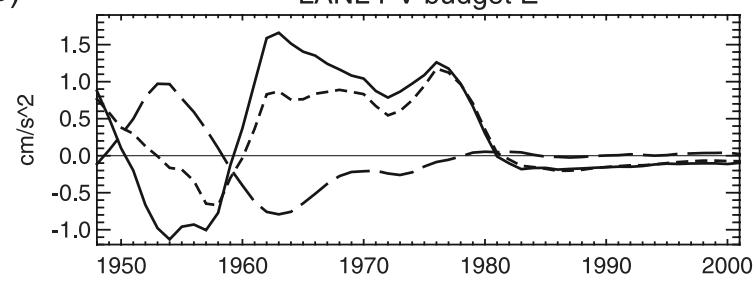

c)

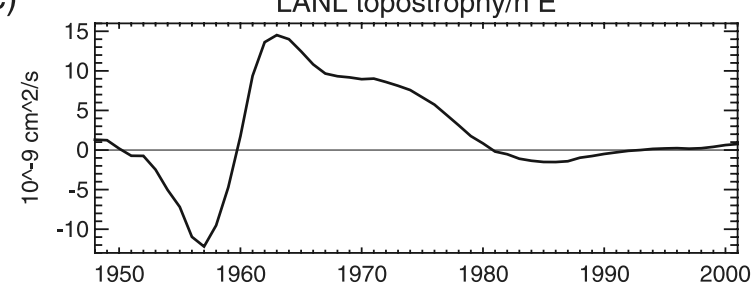

d)

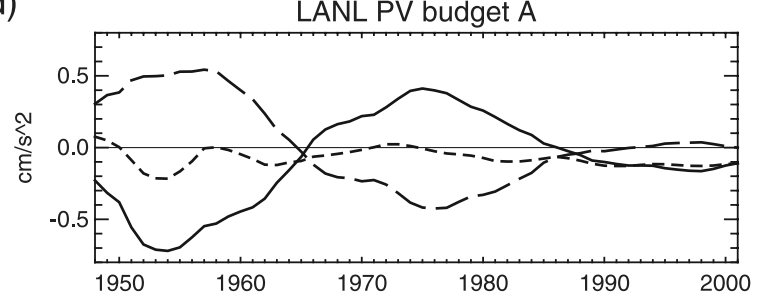

e)

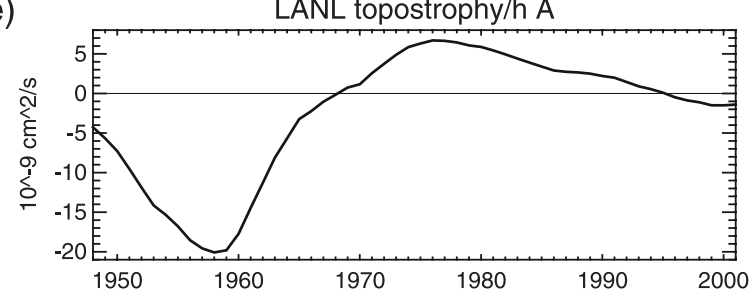

Figure 5. Calculated contributions to the PV budget for the LANL model experiment, as areal integral for the density interval $\sigma=27.8-28.0$ in the (left) Eurasian Basin (E), and the (right) Amerasian Basin (A). (a) Lateral flux of PV into E through Fram Strait (short dashed), St. Anna Trough (long dashed), and the total (solid), (b) PV budget (solid) in E as calculated from total net PV inflow (short dashed) minus the tendency of PV (long dashed), (c) basin mean topostrophy/h in E. (d) PV budget (solid) in A as calculated from total net PV inflow across the Lomonosov Ridge (short dashed) minus the tendency of PV (long dashed), and (e) basin mean topostrophy/h in A. The analysis is based on yearly mean values. The shown time series are filtered with a 3-year running mean.

[20] For the Amerasian Basin the UW experiment exhibits dominance of the PV tendency term with a small contribution from the cross Lomonosov Ridge flux (Figure 4d). For most of the experiment the Amerasian Basin PV budget is positive, as is the topostrophy/h (Figure 4e). In the first years when the PV budget is negative, the balance occurs by anticyclonic boundary currents (i.e. negative topostrophy). While again PV budget and dissipation are able to balance on the long temporal scales, on the shorter timescales nonnegligible differences in the temporal behavior of both indicate vertical PV fluxes to be important.

[21] In contrast to the experiments with the AWI and UW models, the LANL model shows a mostly negative net lateral PV flux into the Eurasian Basin before 1960 and after 1982 (Figure 5a). Despite counteracting PV tendency, the sum stays mostly negative during these years (Figure $5 \mathrm{~b}$ ). The topostrophy/h follows this development closely, indicating a balance by PV dissipation (Figure $5 \mathrm{c}$ ). In the Amerasian Basin we find the PV tendency to be dominant again, with a negative PV budget to be balanced in the first two and the last decade. Indeed the topostrophy/h of the Amerasian Basin follows the budget rather closely suggesting a balance by dissipation. The switch to positive budget in both basins after 1960 (Eurasian) and 1965 (Amerasian) is accompanied by switches of the sense of the boundary currents to cyclonic.
[22] To give an idea of the flow patterns of the respective AWL in each of the model experiments, we show the year 1970. It serves as an example for periods with fully developed cyclonic flow (Figure 6).

[23] All three investigated AOMIP experiments suggest that periods of intense cyclonic circulation in the Eurasian Basin occur during phases of large net PV inflow. Since in each of the experiments the dominant PV inflow occurs via St. Anna Trough, it is obvious to search here for the source areas of this highly stratified water. Dense water from the Barents Sea shelf is known to feed into the trough. Means of 5-year periods characterized by high net PV inflow through St. Anna Trough in the AWI, LANL and UW experiments show widespread areas of elevated PV, mostly in the Barents Sea (Figure 7, left panels). In contrast, 5-year means from periods of low net PV flux through St. Anna Trough exhibit only small areas of elevated PV on the shelf, thus providing no potential source for elevated PV fluxes off the shelf. Note that the high PV areas visible in inner Kara Sea do not contribute to the outflow of PV into St. Anna Trough, which are entirely fed by the high PV from the Barents Sea.

[24] The AOMIP coordinated experiments suggest that in the Eurasian Basin net PV inflow (outflow) is balanced by dissipation due to cyclonic (anticyclonic) boundary current flow. Thus we can find support for the idea of Yang [2005] that net PV inflow into the Arctic Ocean determines the 


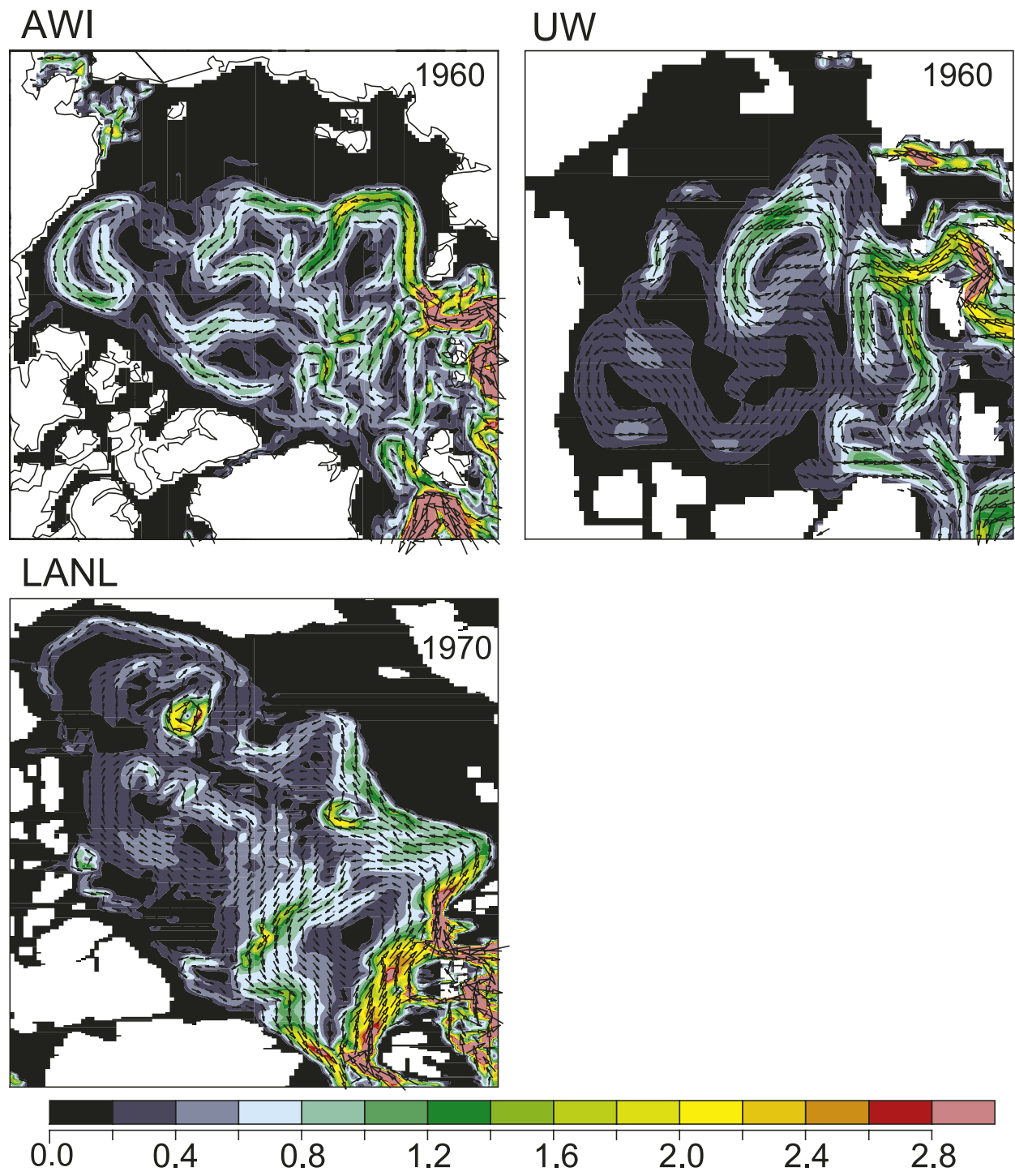

Figure 6. Mean velocity $(\mathrm{cm} / \mathrm{s})$ for the density interval $\sigma=27.8-28.0$ from selected years as example for fully established cyclonic flows: AWI and UW in 1960, LANL 1970. The color code gives velocity in $\mathrm{cm} / \mathrm{s}$. Not all velocity vectors are shown.

sense of rotation of the AWL in the Eurasian Basin. Our results also indicate that the process of water mass conversion in the Barents Sea is a prominent candidate for the production of high PV water and thus intense influence on boundary current flow of the AWL in the Eurasian Basin. However, in the Amerasian Basin net lateral PV flux cannot explain the temporal behavior of the boundary currents at all and thus vertical fluxes of PV have to have an important contribution here.

[25] The switch off of sea surface salinity restoring after year 10 in the AOMIP experiments leads to a strong model drift [see also Häkkinen et al., 2007; Holloway et al., 2007]. As a consequence, a deepening of the density interfaces chosen as representative for the AWL in the first decades sets in, which is followed by a gradual shut-down of the inflow of PV into the AWL through St. Anna Trough. We cannot exclude the possibility that the drift of model hydrographies has an influence on our conclusions with respect to AWL driving forces. We therefore extend our investigation to the analysis of a further experiment in which the continuous use of surface salinity restoring keeps up a stable inflow of dense water from the Barents Sea to the AWL.

\subsection{PV Analysis of AWI_CLIMAT and AWI_NCEP Experiments}

[26] In the following section we extend our PV analysis to two experiments performed with the AWI NAOSIM model: AWI_CLIMAT and AWI_NCEP. The experimental setup is similar to the AOMIP runs with two important differences: the initial condition for AWI NCEP is not the PHC climatology, but the 50th year of a spin-up run, AWI CLIMAT, that was driven with atmospheric data from a climatology derived from the ERA15 atmospheric reanalysis data [Röske, 2001]. The second difference is the use of surface salinity restoring to sea surface salinity climatology for the entire period of the experiments in both model experiments (restoring timescale is 180 days). The sea surface salinity climatology has been constructed by 

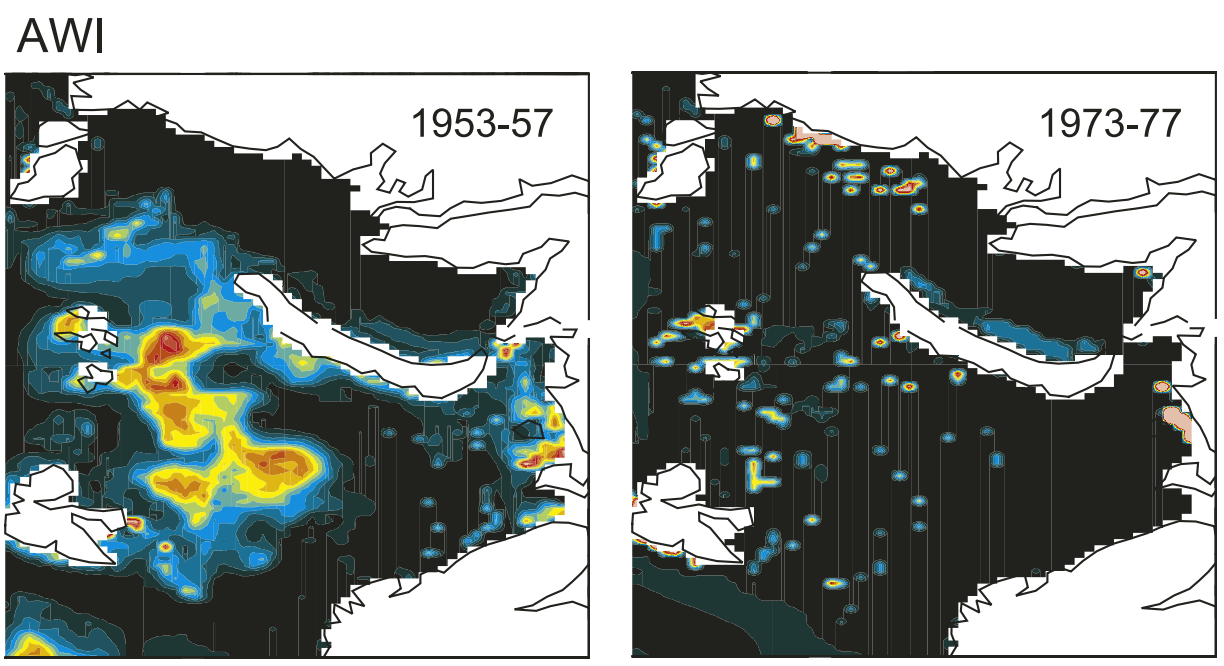

LANL
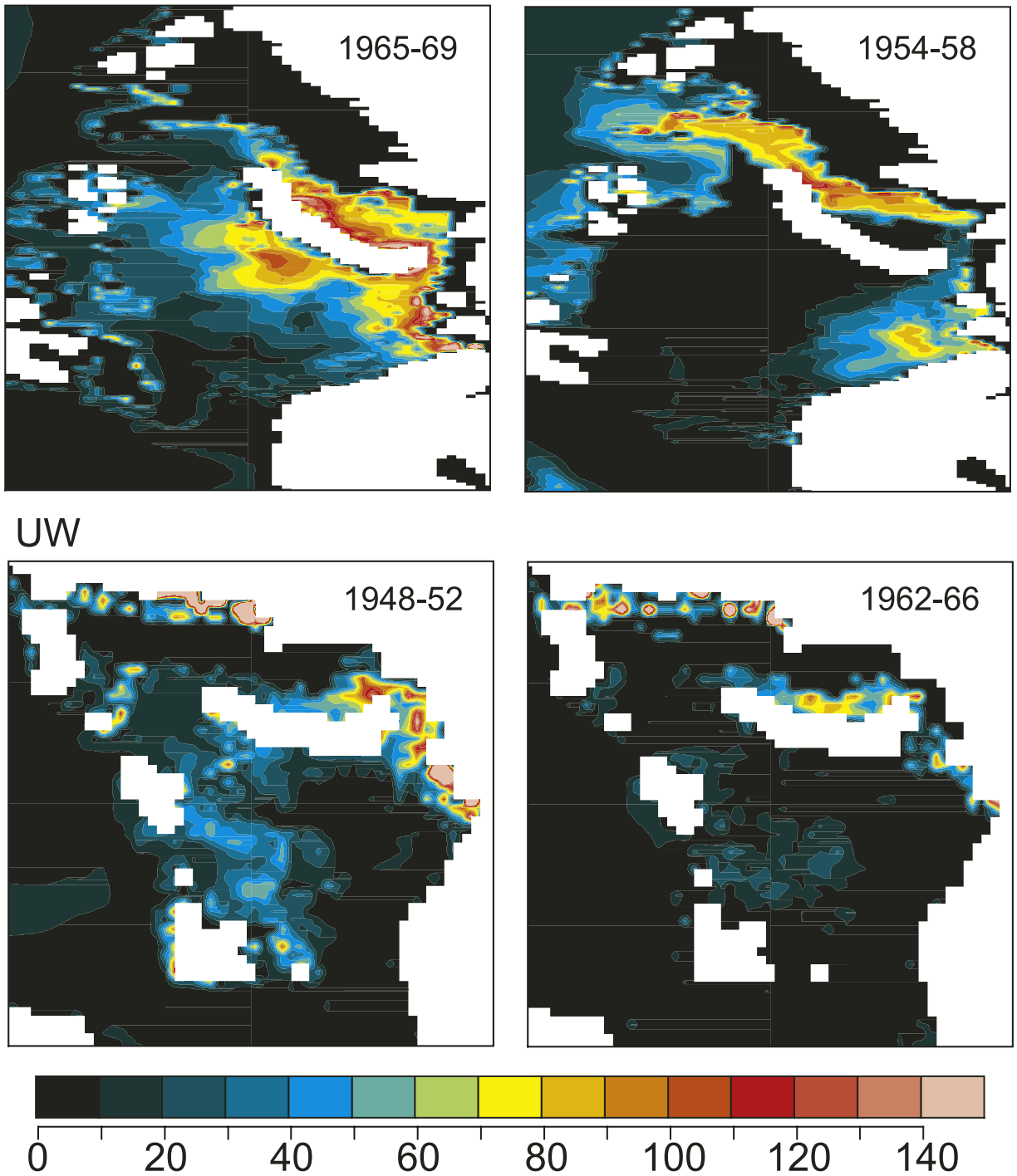

Figure 7. Distribution of PV $\left(10^{-11} \mathrm{~m}^{-1} \mathrm{~s}^{-1}\right)$ for the density interval $\sigma=27.8-28.0$ in the Barents and Kara Sea from the AOMIP model experiments (AWI, LANL, UW). Left (right) panels show 5-year means from periods of high (low) PV flux across the St. Anna Trough into the Arctic Basin. 
AWI Climat

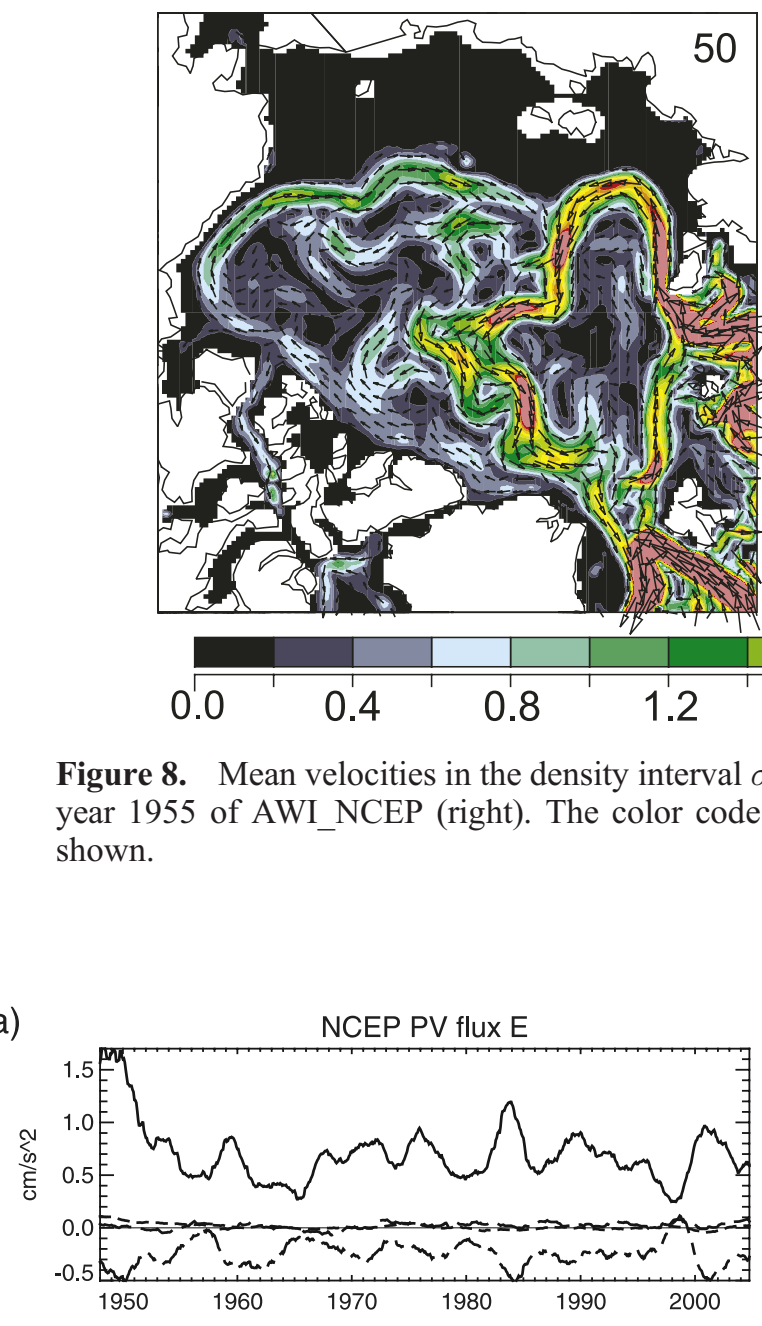

b)

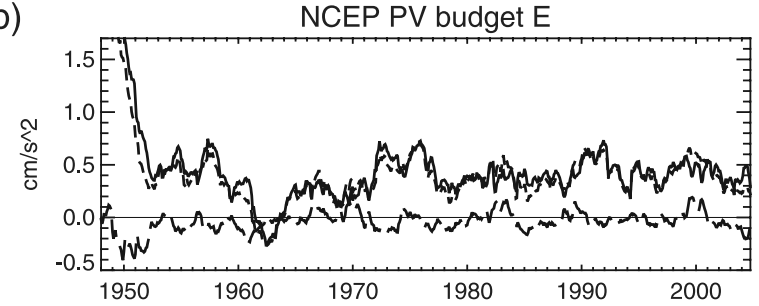

c)

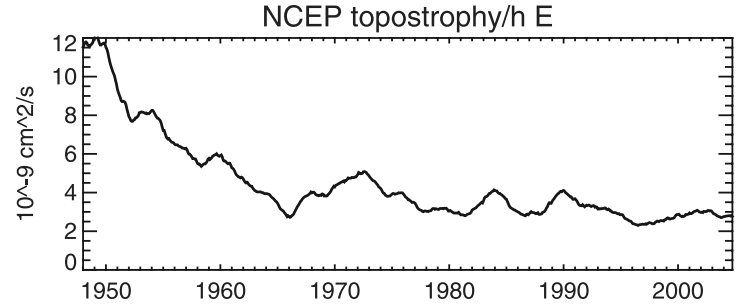
shown.

a)
AWI NCEP

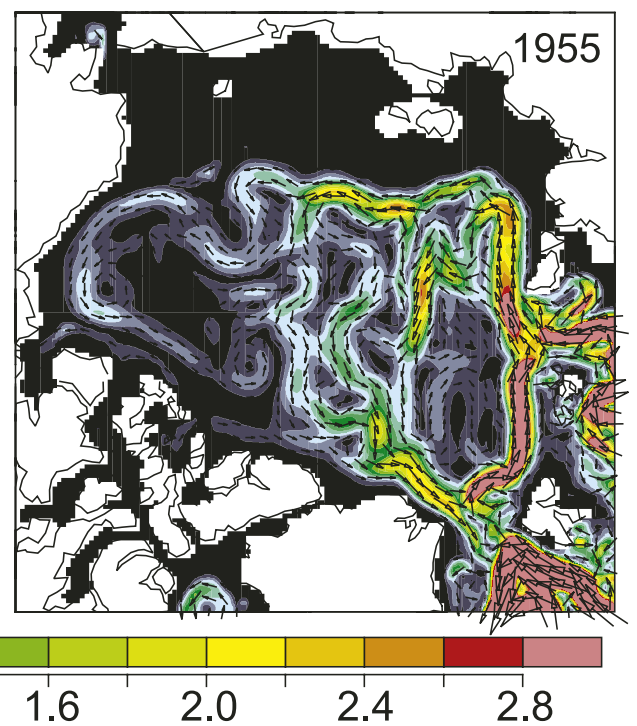

Figure 8. Mean velocities in the density interval $\sigma=27.7-28.1$ in year 50 of AWI_CLIMAT (left) and year 1955 of AWI_NCEP (right). The color code gives velocity in $\mathrm{cm} / \mathrm{s}$. Not every velocity vector is

d)

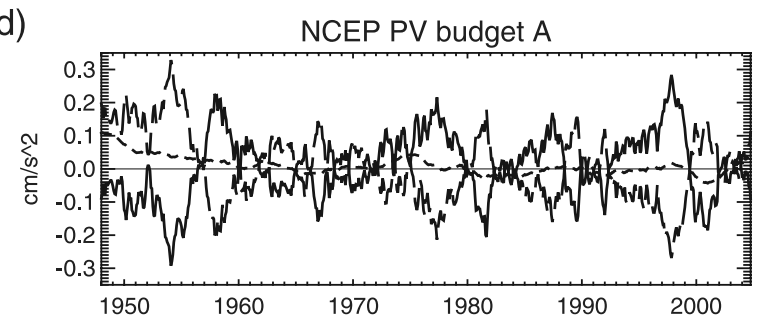

e)

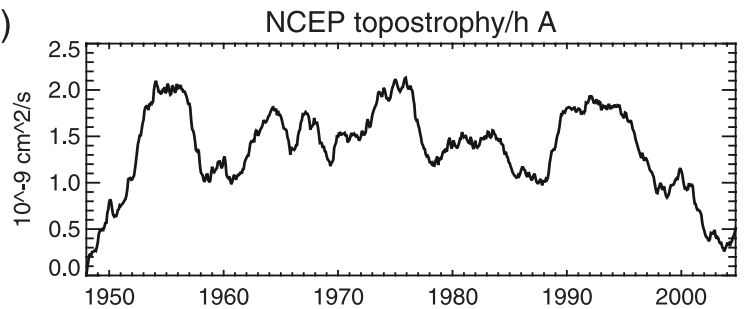

Figure 9. Calculated contributions to the PV budget for the AWI_NCEP experiment, as areal integral for the density interval $\sigma=27.7-28.1$ in the (left) Eurasian Basin (E), and the (right) Amerasian Basin (A). (a) Lateral flux of PV into E through Fram Strait (short dashed), St. Anna Trough (long dashed), the Franz-Josef-Land to Svalbard section (short-long dashed) and the total (solid), (b) PV budget (solid) in $\mathrm{E}$ as calculated from total net PV inflow (short dashed) minus the tendency of PV (long dashed), (c) basin mean topostrophy/h in E. (d) PV budget (solid) in A as calculated from total net PV inflow across the Lomonosov Ridge (short dashed) minus the tendency of PV (long dashed), and (e) basin mean topostrophy/h in A. The analysis is based on monthly mean values. The shown time series are filtered with a 25-months running mean. 


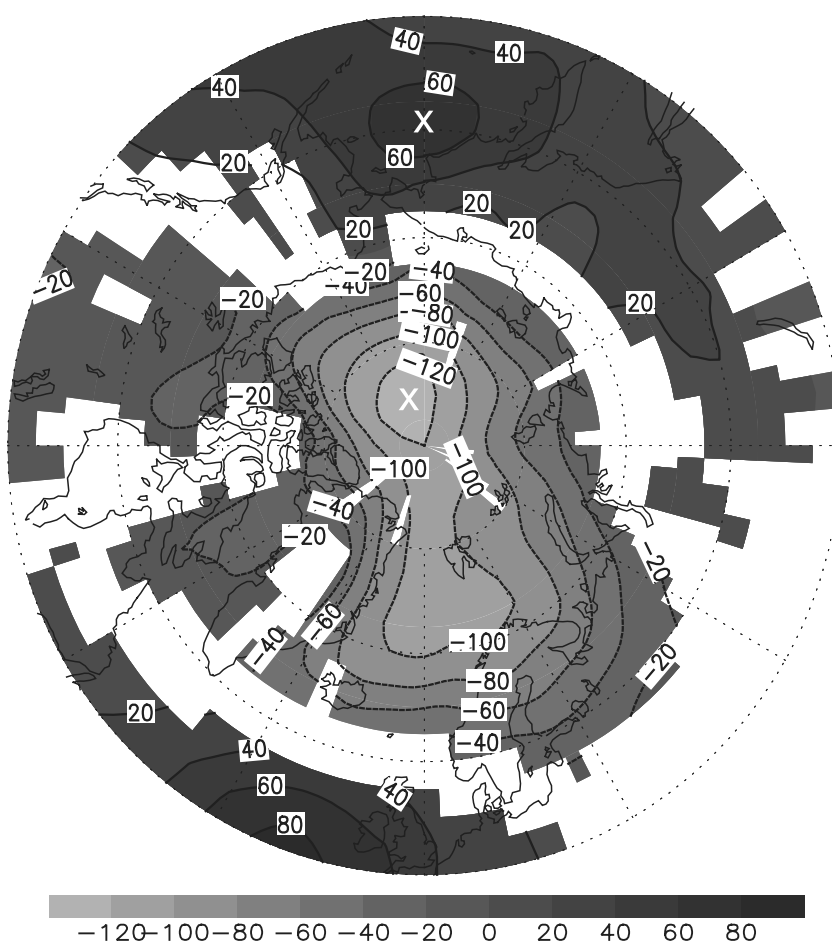

Figure 10. SLP $(\mathrm{Pa})$ regressed on topostrophy/h integrated over the Amerasian Basin. The regression is based on winter-centered yearly means from the AWI_NCEP experiment and SLP data from NCEP. Only areas significant at the 99\% level (F-Test with 19 degrees of freedom) are plotted. White crosses denote the centers of action for the SLP gradient between the Bering Sea and the central Canadian Basin used in the text and Figures 13 and 14. The first ten years have been omitted from this analysis.

merging the yearly mean salinities from the EWG data set [NSIDC Environmental Working Group, 1997] with salinities from Levitus et al. [1994] outside of the EWG domain, a dataset which is very close to the sea surface salinity of the PHC climatology used for the AOMIP experiments. The experimental setup is described in more detail by Kauker et al. [2005]. Driven with atmospheric data from the NCEP reanalysis, AWI NCEP has been used successfully for the Arctic and the Nordic Seas for a number of investigations [e.g., Gerdes et al., 2003, 2005; Kauker et al., 2003; Karcher et al., 2003a, 2003b, 2005]. We have chosen a density interval of $\sigma=27.8-28.1$ to represent the AWL which is more appropriate for this experiment than the interval used for the AOMIP experiments, for which the interval had to be smaller due to the model drift. Qualitatively the results are independent of the precise choice of the density interval.

[27] Two snapshots of mean velocities in the AWL density interval illustrate the change of flow patterns from the AWI_CLIMAT to the AWI_NCEP experiment. The AWI CLIMAT experiment exhibits cyclonic circulation in the Eurasian Basin and anticyclonic motion in large parts of the Amerasian Basin which is stable during almost the entire experiment (Figure 8). The annual mean net lateral PV flux in year 50 for AWI_CLIMAT is about $2 \mathrm{~cm} / \mathrm{s}^{2}$ integrated over St. Anna Trough. No significant net contri- bution from Fram Strait occurs, the tendency is small. In case the vertical flux of PV were small we would expect the large net PV input to be balanced by PV dissipation in cyclonic boundary currents. While this situation in fact holds for the Eurasian Basin, this is not the case in the Amerasian Basin.

[28] In AWI NCEP in the initial year 1948 the situation is still very similar to the year 50 of AWI CLIMAT. In the following decades, the net PV input to the Eurasian Basin reduces to about half but stays positive, with St. Anna Trough again providing the dominant input (Figures 9a and $9 \mathrm{~b}$ ). In contrast to the AOMIP experiments here also flux of PV across the line Franz-Josef-Land to Svalbard has to be included, which is mostly directed out of the Eurasian Basin. The tendency of PV stays small. Again, if vertical fluxes of PV were small, too, we expect topostrophy to follow the budget, indicating the balance to be closed by dissipation in the boundary currents. From visual inspection this is the case on the long timescales, but not obvious on the interannual timescale (Figure 9c). We will perform a more quantitative analysis later on.

[29] In AWI_NCEP after a start from anticyclonic motion in the southern parts of the Amerasian Basin and about zero spatial integral of topostrophy/h (Figure 9e) the circulation is dominated by cyclonic motion after a few years (Figure 8), as mirrored by positive topostrophy/h. Though now both basins are dominated by cyclonic motion, the Amerasian Basin situation differs completely from the Eurasian Basin. As already found for the AOMIP experiments, the dominant balance in the Amerasian Basin is not between dissipation and lateral flux of PV: the difference lateral PV fluxes and PV tendency shows very different temporal development than topostrophy/h, suggesting that vertical fluxes of PV which are able to balance the dissipative loss due to the cyclonic currents, have to be considered.

[30] Can we find external forces which are likely to drive vertical PV fluxes at the upper interface of the AWL? A primary candidate is the wind field, which drives the upper layer flow resulting in vertical PV fluxes at the upper interface of the AW layer due to frictional effects, deformation and stretching. A regression of winter centered yearly means of northern-hemispheric SLP on topostrophy/h in the Amerasian Basin (Figure 10) depicts a weakened high pressure center over the Amerasian Basin and extension into the northern Nordic Sea during periods of strong topostrophy/h. This indicates an influence of the local wind field over the Amerasian Basin with strongest gradients perpendicular to the basin perimeter in the Beaufort and Chukchi Seas. Weaker positive SLP anomalies occur over the Bering Sea and in the northeastern North Atlantic. The SLP pattern (Figure 10) with its gradient between the North Atlantic and the Nordic Sea bears resemblance with the AO/NAO pattern, though with a shifted northern center of action. We therefore test the correlation of the basin topostrophy/h with the NAO index [van Loon and Rodgers, 1978; Hurrell, 1995] (Figure 14b), too. However, except for some years, no significant correlation is found for either of the two basins (Figure 13d).

[31] For the Eurasian Basin the regression of wintercentered yearly mean topostrophy/h is not significant even on the $90 \%$ level (F-test). However, as we have deduced from Figures $9 \mathrm{~b}$ and $9 \mathrm{c}$, topostrophy/h and the PV budget 
a)

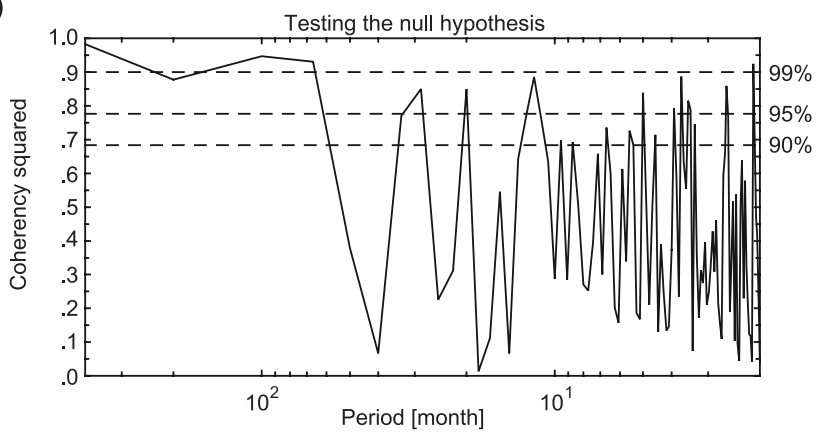

b)

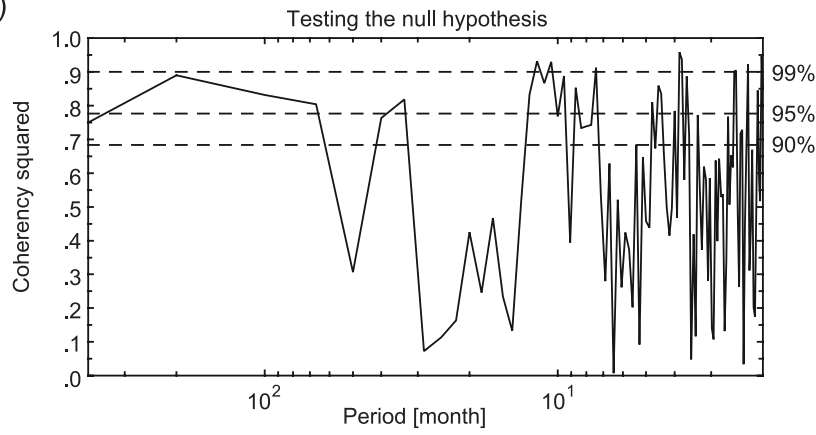

Figure 11. Cross spectra of the Eurasian Basin topostrophy/h with (a) the PV balance of the Eurasian Basin and (b) the net PV inflow via St. Anna Trough. Stippled lines show confidence levels estimated by a Bartlett procedure. A chunk length of 200 months has been used. The first ten years have been omitted from this analysis.

dominated by lateral PV inflow via St. Anna Trough are related on long timescales. This is confirmed by cross spectra analyses of the Eurasian Basin PV budget and topostrophy/h and of PV inflow through St. Anna Trough and topostrophy/h both showing significant coherence on timescales larger than 5-6 years (Figure 11). Also in the AOMIP experiments we saw a strong link of the Eurasian Basin topostrophy/h and the PV inflow through St. Anna Trough on long timescales (Figures $3 b$ and 3c; Figures $4 b$ and $4 \mathrm{c}$; Figures $5 \mathrm{~b}$ and $5 \mathrm{c}$ ). The PV inflow thus seems to pose a constraint for cyclonic flow in this basin.

[32] In the AOMIP experiments we also found elevated levels of PV on the Barents Sea shelf in periods of high PV inflow through St. Anna Trough. Can we confirm this finding in AWI_NCEP and identify the forcing factors for this process?

[33] To answer this question, we first check the connection with the large scale SLP field. A regression of wintercentered yearly means of the northern hemispheric SLP on the St. Anna Trough PV inflow (Figure 12) exhibits a pattern with a strong negative SLP anomaly centered over the Svalbard/Western Eurasian Basin region, extending south covering the entire Nordic Seas. Knowing that the transport of water across the Barents and Kara Sea shelf is intensified in periods of high NAO [e.g., Karcher et al., 2003a, 2003b], this pattern might suggest that the inflow of PV via St. Anna Trough is mostly driven by the intensity of the flow through the trough. This is, however, not the case. We calculate separate running correlations of the PV inflow through St. Anna Trough with both components: the flow velocity into the AWL integrated across St. Anna Trough and the PV integrated across the section to be transported into the AWL (Figure 13a). We use a 20 year window. The correlation of PV inflow with the velocity across the section is consistently lower than with the mean PV at the section. We thus conclude that production of PV on the shelf is more or at least equally important for the PV inflow than the throughflow velocities.

[34] To illuminate the temporal changes of the relation between topostrophy/h in the two basins with lateral PV fluxes and wind forcing, we calculated running correlations between these parameters, too. The link of topostrophy/h in the Eurasian Basin with the net lateral PV flux through St. Anna Trough is confirmed with correlations higher than 0.4 from 1972 on (center of the window) (Figure 13b). The strongest correlation occurs during the latter period of the experiment. For the Amerasian Basin the running correlation is low over the entire period. The physical mechanism responsible for production of high PV (i.e. highly stratified) water on the Barents Sea shelf should be elucidated further by linking the variability of net PV flux through St. Anna Trough to the dense water formation processes further upstream. Water entering the Barents Sea from the Nordic Sea has a travel time of about two years to cross the shelf before it leaves through St. Anna Trough. During its passage, heat and salt exchanges at the surface are integrated. In AWI_NCEP large buoyancy loss is associated with a

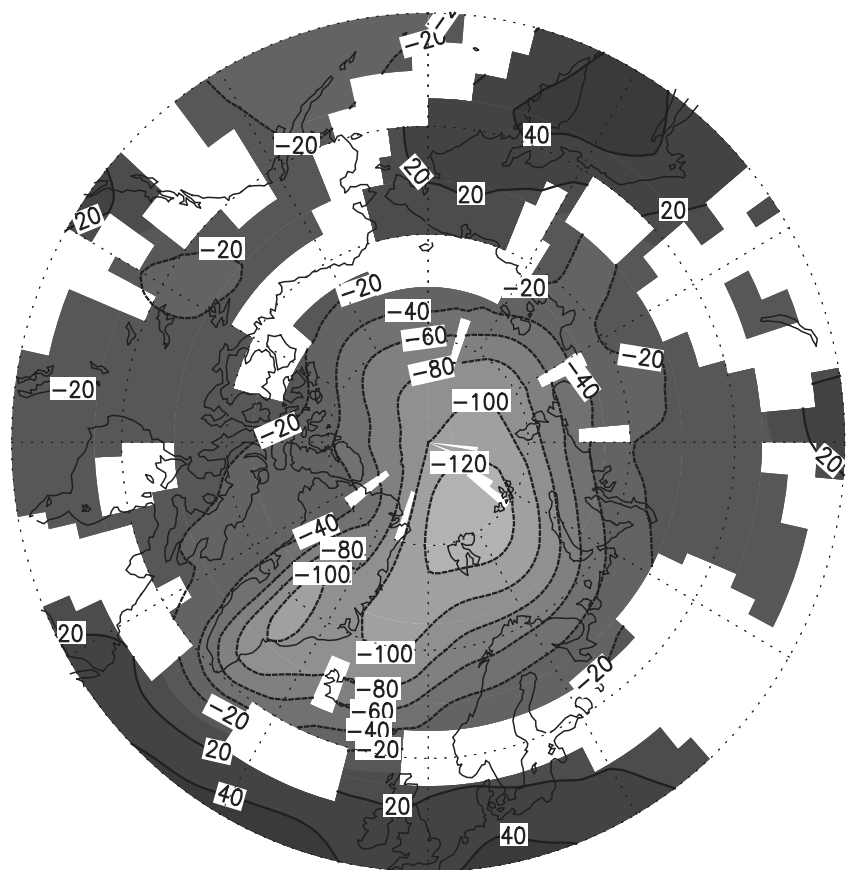

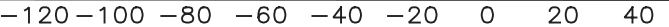

Figure 12. SLP $(\mathrm{Pa})$ regressed on $\mathrm{PV}$ inflow to the Eurasian Basin via St. Anna Trough. The regression is based on winter-centered yearly means from the AWI NCEP experiment and SLP data from NCEP. Only areas significant at the 99\% level (F-Test with 19 degrees of freedom) are plotted. The first ten years have been omitted from this analysis. 
a)

b)
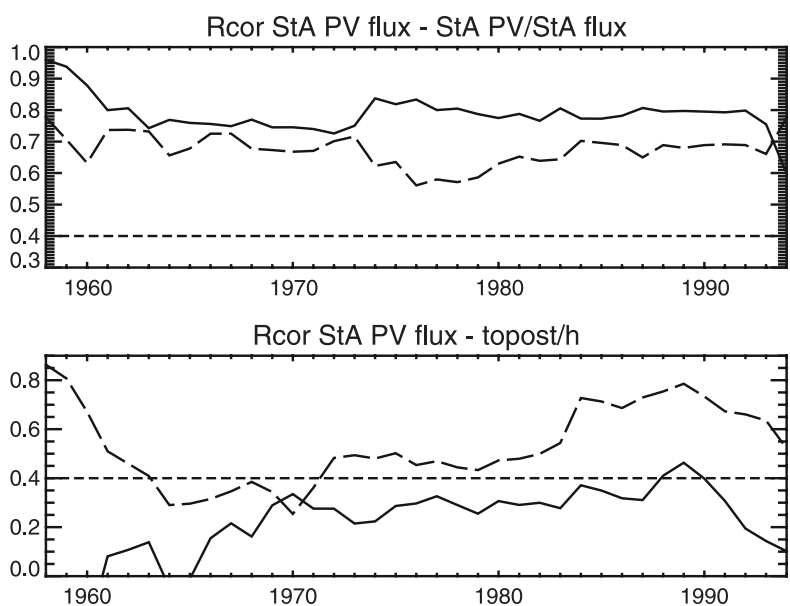

c)

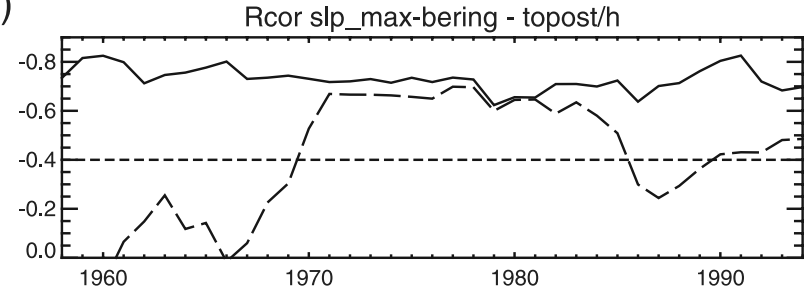

d)

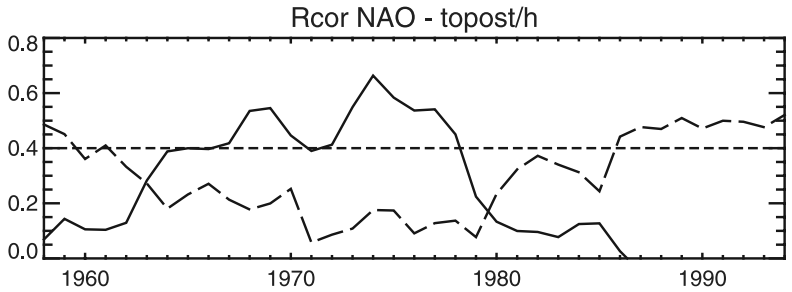

Figure 13. (a) Running correlations for the AWL density interval $(\sigma=27.7-28.1)$ of the net PV inflow through St. Anna Trough with the mean PV advected through St. Anna Trough (solid) and with the mean velocity through the trough (stippled). (b) Running correlations for the AWL density interval $(\sigma=27.7-28.1)$ of the mean topostrophy/h in Amerasian Basin (solid) and the Eurasian Basin (stippled) with the net PV inflow through St. Anna Trough. (c) Running correlations for the AWL density interval $(\sigma=27.7-28.1)$ of the mean topostrophy/h in Amerasian Basin (solid) and the Eurasian Basin (stippled) with the SLP difference between the Bering Sea and the Canadian Basin, and (d) the NAO index after Hurrell [1995] (see Figure 14). The running correlations are based on winter-centered means with a 20 -year window. The time axis gives the middle year of a window, e.g. 1960 denotes the years from 1950-1969. The stippled line shows the 99\% confidence interval estimated with a Monte Carlo test by fitting $\mathrm{AR}(1)$ random time series to the data. See Figure 10 for the locations of the Bering Sea and Canadian Basin SLP gradient locations and Figure 14 for the respective time series.

reduced ice cover two years before high PV flux enters the Eurasian Basin, as can be seen from ice-concentration composites for high and low PV flux years (see Figure 14c) and regressed surface buoyancy fluxes on the net PV flux through St. Anna Trough (time lag of two years) (Figure 15a).
The composites have been constructed by averaging over years in which the PV flux anomaly through St. Anna Trough exceeds more than one standard deviation (see stippled lines in Figure 14c). The areas depicted by the model in the eastern Barents Sea near Novaya Semlya, are consistent with regions of large buoyancy loss derived from observational results [e.g., Schauer et al., 2002]. As a consequence of the buoyancy loss in the Barents Sea dense water forms in winter and the water column is homogenized at the formation sites. An example for the section FranzJosef-Land to Novaya Semlya is shown in Figures 16a and $16 \mathrm{~b}$ (see Figure $15 \mathrm{~b}$ for its location). In this area the dominant mechanism for the formation of dense water is brine release by ice formation in the lee polyna west of the island, which is subsequently advected northward [Karcher et al., 2003a, 2003b]. The somewhat counter-intuitive increase of high PV water production with intense densewater formation is understandable when taking into account the seasonal cycle of stratification. In summer the upper

a)

b)

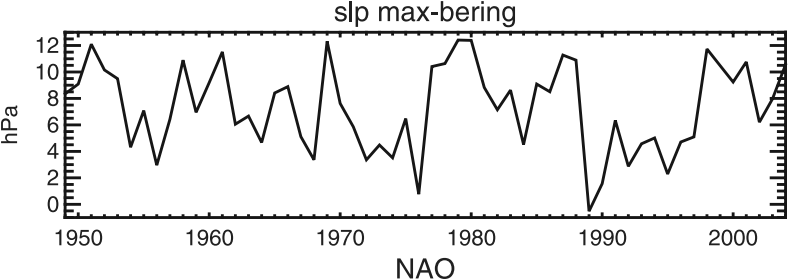

c)
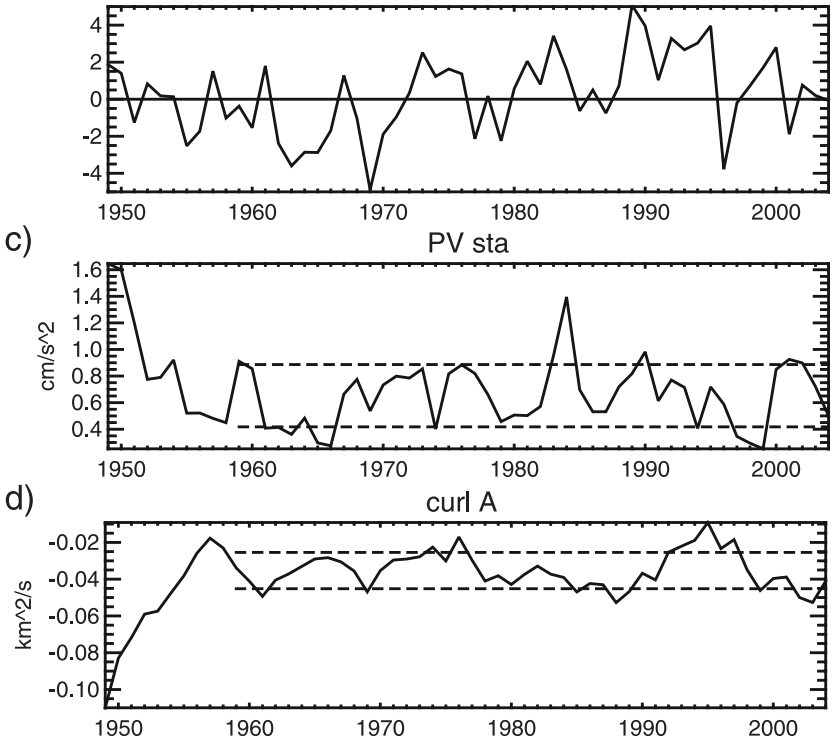

Figure 14. Winter-centered yearly means (a) SLP difference between the center of the Canadian Basin and the Bering Sea (see Figure 10 for the locations), (b) the NAO index after Hurrell [1995], (c) the net PV inflow through St. Anna Trough from the AWI NCEP experiment, and (d) the curl of the upper $60 \mathrm{~m}$ velocities in the Amerasian Basin of the AWI NCEP experiment. The stippled lines in (c) and (d) indicated the mean \pm 1 standard deviation. The years exceeding the upper one standard deviation lines are used to construct composites for high states, while years falling below the lower one standard deviation lines are used to construct composites for low states. The first 10 years were omitted from the standard deviation calculations. 
a)

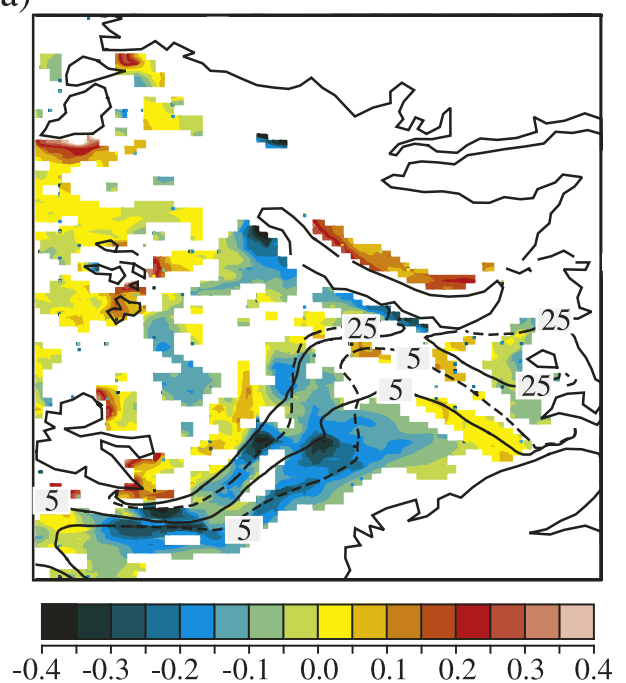

b)

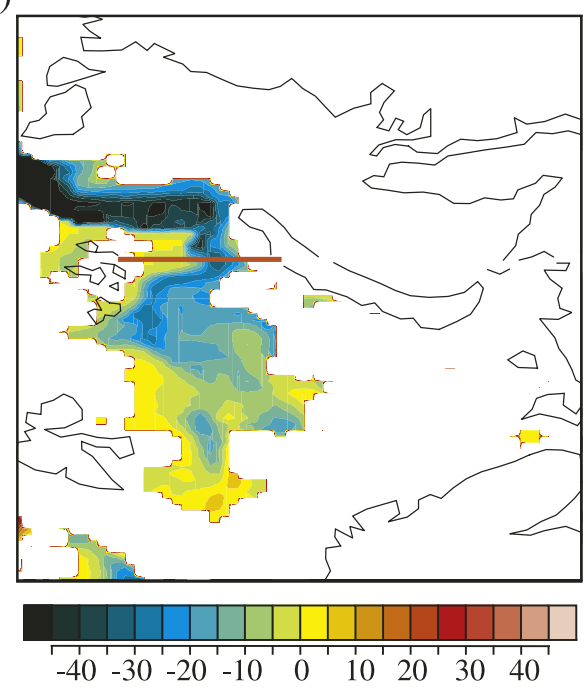

Figure 15. (a) Surface buoyancy fluxes $\left(\mathrm{N} / \mathrm{m}^{2} \mathrm{~s}\right)$ regressed on the net PV flux through St. Anna Trough with a time lag of 2 years. The solid (dashed) black lines show the $5 \%$ and $25 \%$ ice concentration for composites of years with a high (low) net PV flux trough St. Anna Trough (see Figure 13c). (b) Anomaly of the lower AW interface $(\sigma=28.1)$ depth, regressed on net PV flux across St. Anna Trough (no time lag). Only values significant at the $99 \%$ level are shown (F-test, 19 degrees of freedom). Negative values are equivalent to shallower depth. The red line denotes the section presented in Figure 16, connecting Franz Josef Land with Novaya Semlya. All data are based on winter-centered yearly means. The first 10 years were omitted from the calculations.

water column restratifies (Figures 16c and 16d) where larger production of bottom water $(\sigma>28.1)$ in the preceding winter leads to a stronger stratification and hence higher PV values for the density level 27.7-28.1. Subsequently higher PV water enters St. Anna Trough. The simulated density structure on the section from Franz Josef Land to Novaya Semlya in summer compares well with observations [Schauer et al., 2002], shown in Figure 16e. A regression of the lower interface height of the AWL on PV fluxes through St. Anna Trough (Figure 15b) indicates the spatial distribution of high PV water storage and pathway. These results confirm that intense dense water production on the Barents Sea shelf is the reason for the very large PV input from St. Anna Trough. In this process we also find the source for the extremely large PV input in the AWI_CLIMAT experiment and the initial year of AWI_NCEP. In the case of AWI CLIMAT, atmospheric forcing favourable for dense water production lasts for a period of 50 seasons, evidenced by the very large buoyancy loss in the western Barents and the Kara Sea in AWI_CLIMAT in comparison to AWI_NCEP (Figure 17a).

[35] Turning back to the physical mechanisms related to the AWL flow in the Amerasian Basin, we take the SLP gradient between the centers of action in the Bering Sea and the central Canadian Basin (Figure 14a) as a measure of the intensity of local Amerasian Basin wind forcing (see white crosses in Figure 10). A calculation of its running correlation with topostrophy/h results in correlation coefficients around -0.7 over the entire simulation period (Figure 13c). This suggests significant influence of the local wind stress over the Canadian Basin continental slopes on the flow at AWL depth: periods of strong cyclonic flow in the AWL occur when the gradient is strongly negative, leading to a weak Beaufort Gyre forcing. This close match of the inverse SLP gradient Bering Sea-Canadian Basin (inverse of Figure 14a), the curl of the surface velocities (Figure 14d) and the AWL topostrophy/h in the Amerasian Basin (Figure 9e) is persistent throughout the simulation, with two notable exceptions. As a consequence of the spin-up process, the curl of the surface flow and topstrophy/h are not yet following the SLP gradient in the first 5-8 years. The second exception occurs in the last decade of the simulation when the SLP gradient and the surface flow curl match, while the topostrophy/h is decoupled and continues to decrease instead of levelling off, the reason for which is unclear.

[36] The link between the circulation of the AWL in the Amerasian Basin and the local wind forcing can be understood as a response to forces acting via the directly driven ice and surface ocean flows, e.g. the Beaufort Gyre. Whether this is mainly realized by fast-acting, barotropic pressure gradients due to changes in the surface elevation or through the restructuring of the upper ocean density fields and alteration of the halocline depth remains to be investigated. In the latter case we expect a delayed response of the circulation. The timescale for this adaptation process can be estimated from the spin-up of the curl in the upper water column in the Amerasian Basin during the first 5-8 years (Figure 14d).

[37] The unrealistically stable atmospheric forcing from the climatology in case of AWI_CLIMAT, which was responsible for the very strong PV inflow into the Eurasian Basin, is also responsible for the intense anticyclonic movement of the Amerasian Basin AWL in this experiment. The OMIP climatology repeats the same seasonal cycle of atmospheric forcing each year and its continuous high 

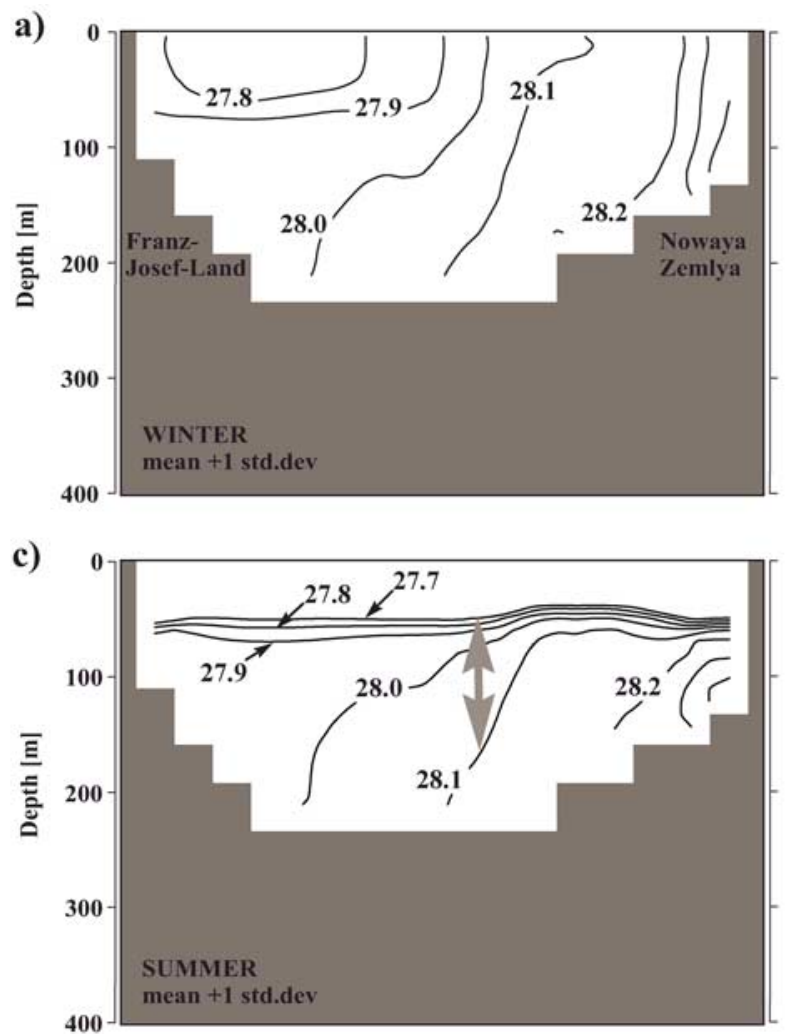
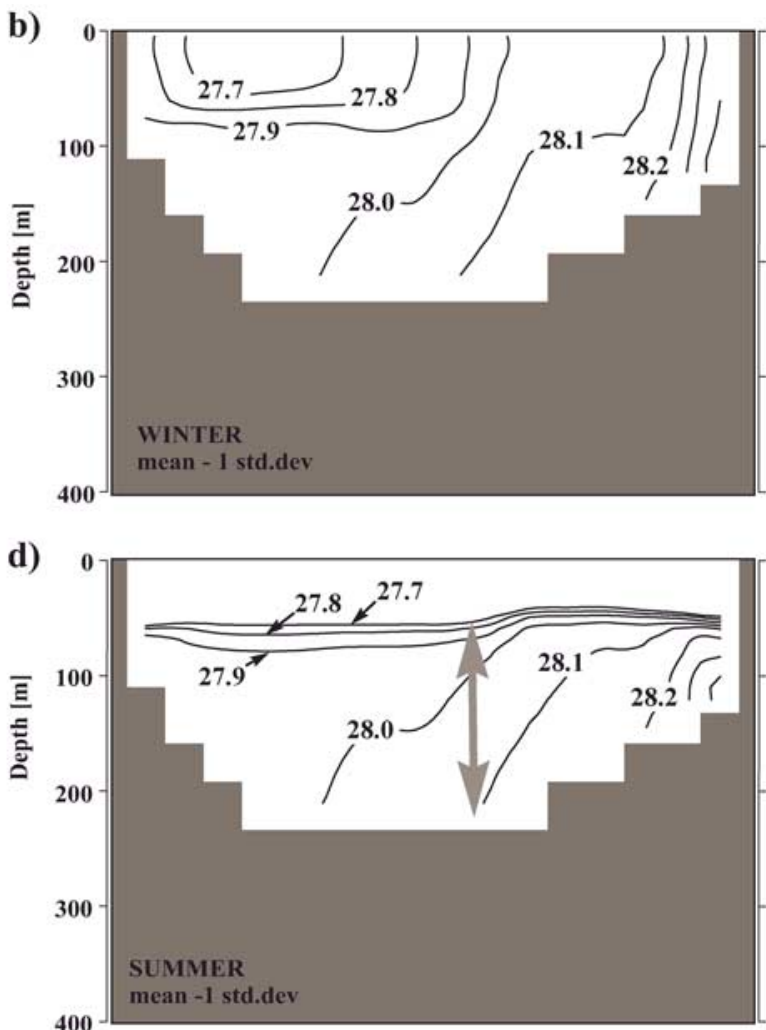

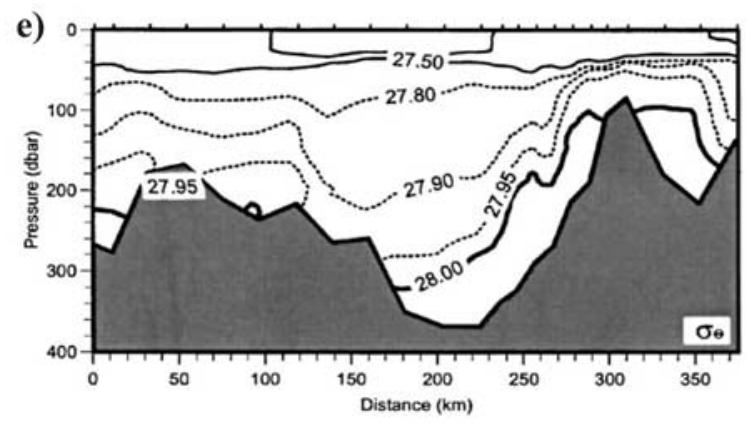

Figure 16. Density on a vertical section from Franz Josef Land to northern Novaya Semlya (see Figure 14b), for years of high ( $a, c)$ and low (b, d) PV flux through St. Anna Trough during winter months (FMA) (a, b) and summer months (JAS) (c, d). The density has been regressed on the PV flux through St. Anna Trough. Panels for high PV flux are constructed by adding the mean density to the regressed density pattern for one standard deviation of PV flux. Panels for low PV flux are constructed by subtracting the regressed density pattern for one standard deviation of PV flux from the mean density. The range $\sigma>27.7$ is shown with an isoline interval of 0.1. (e) An observed section in the vicinity of the model section from summer 1991 (from Schauer et al. [2002], Copyright (2002), with permission from Elsevier). Differences in bottom depth are due to insufficiencies in the effective model topography.

pressure system over the central Arctic acts as a permanent anticyclonic forcing for the ocean. Thus the hydrography can adjust completely and is able to produce a very intense Beaufort Gyre, expressed in a large, deep depression of the halocline. In reality, this situation is not realized for periods longer than several years [Proshutinsky and Johnson, 1997]. In contrast, in the AWI_NCEP experiment, as well as in the real Arctic Ocean, the intensity and location of the central Arctic high pressure system varies considerably on the pentadal to decadal timescale, not allowing the hydrography to fully adjust with a deep gyre as is the case in AWI_CLIMAT. The large difference between the two experiments in the Beaufort Gyre intensity and the density structure in the Canadian Basin is most striking in the depth of the density interfaces separating the Polar Surface Water from the upper Atlantic Water (Figures 17b-17d). Even in years of strong anticyclonic surface currents in the Amerasian Basin (Figure 17c) the Beaufort Gyre is much weaker and shallower than in the AWI_CLIMAT experiment.

[38] Comparing the composites of upper AWL interface depth for strong and weak anticyclonic surface flows from AWI NCEP (Figures 17c and 17d), we find that the Beaufort Gyre is clearly weaker and smaller in years of weak anticyclonic curl of surface flow in contrast to strong 
a)

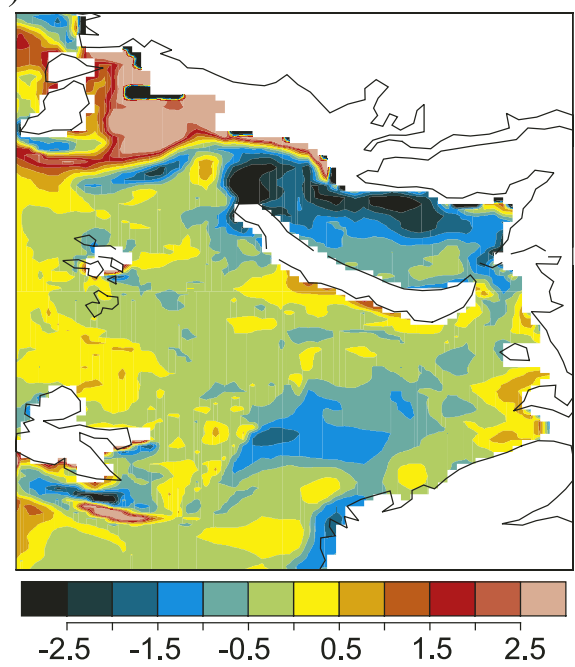

c)

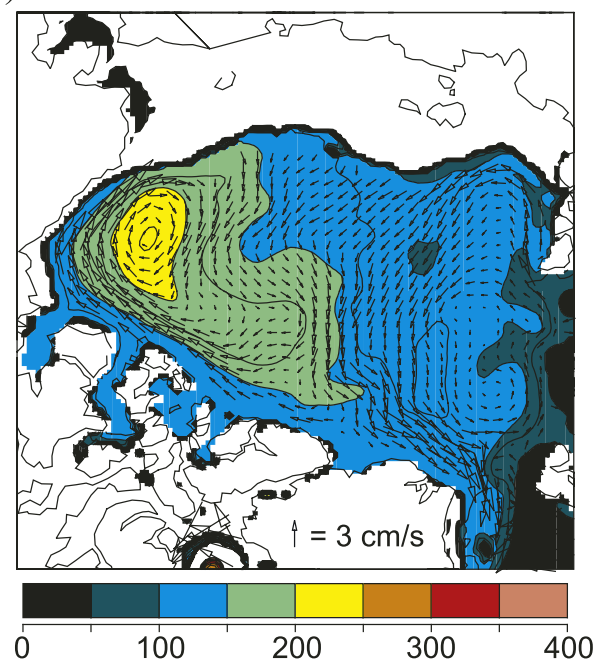

b)

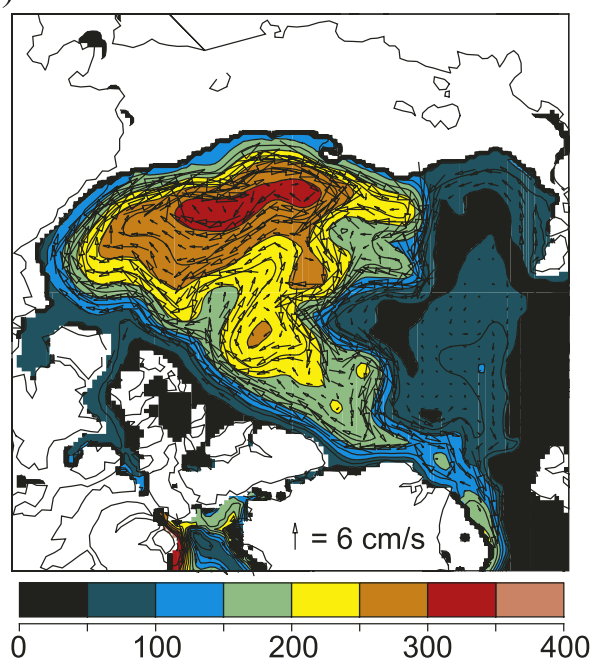

d)

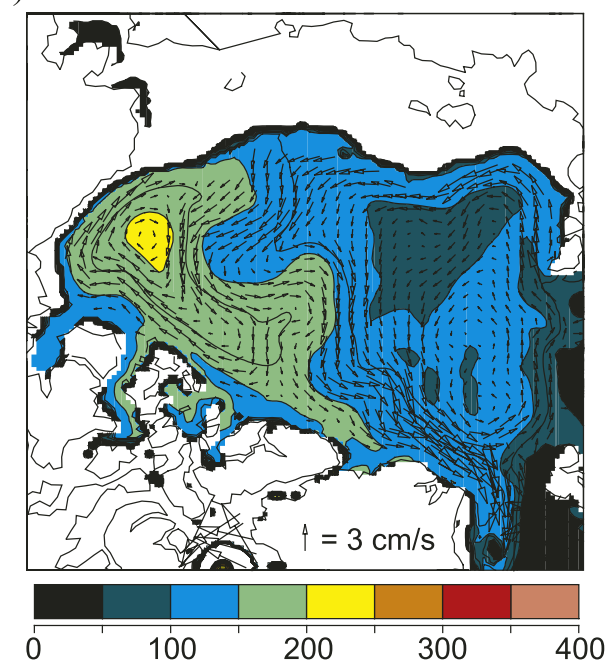

Figure 17. (a) Difference of surface buoyancy flux between AWI_CLIMAT and AWI_NCEP in the Barents Sea. Depth of the upper interface (m) of the density interval $\sigma=27.7-28.1$ (color code) and the mean velocity of the upper $60 \mathrm{~m}$ (vectors) in (b) year 50 of AWI CLIMAT, and composites of years with (c) strong and (d) weak anticyclonic curl of the upper $60 \mathrm{~m}$ velocities in the Amerasian Basin of AWI_NCEP (see Figure 14d).

years, with less intense interface height gradients over the Canadian Basin slopes. In contrast to AWI CLIMAT the AWL boundary current in the AWI_NCEP is able to develop as a counter-current to the surface flows.

\section{Conclusions}

[39] A comparison of existing, diverse, coupled ice-ocean model experiments of the Arctic Ocean reveals a great variety of realizations of intensity, pathway and even sense of rotation of the boundary flows of the AWL in the Arctic Ocean [e.g., Häkkinen and Mellor, 1992; Holland et al., 1996; Gerdes and Schauer, 1997; Nazarenko et al., 1998; Karcher and Oberhuber, 2002; Karcher et al., 2003a, 2003b].

[40] We use a small subset of models from the coordinated experiment to investigate the dynamics of AWL circulation in the Arctic Ocean, in order to better understand reasons for the diverse model response and the dynamics of the Atlantic Water circulation the Arctic Ocean. In addition, we utilize other experiments run with AOMIP models but different configuration. As a convenient measure of the AWL boundary current intensity and direction we employ "topostrophy" introduced by Holloway et al. [2007]. High positive topostrophy is equivalent to strong cyclonic flow above steep topography, with the shallow depths to the right.

[41] Inspired by a recent investigation of Yang [2005], we test the models' Atlantic Water flow against the net inflow of PV. Following Yang [2005], the net inflow (outflow) of PV determines the sense of rotation in the Arctic basins due to the necessary balancing of the PV flux by dissipation which in turn implies cyclonic (anticyclonic) flow of the Atlantic Water boundary currents. His results are based on theoretical considerations and experiments with a highly 
idealized, steady state, barotropic model of the Arctic Ocean.

[42] The AOMIP model experiments we included in this study (AWI, LANL and UW) show a strong link of high PV flux via St. Anna Trough with topostrophy in the Eurasian Basin. The source for this highly stratified water is the Barents Sea. We find that periods of high net PV inflow occur when a reservoir of water with elevated $\mathrm{PV}$ is available on the shelf. Our results indicate that a net input of PV is an important ingredient for the establishment of a cyclonic flow of the AWL in the Eurasian Basin in these model experiments, while anticyclonic flow in the Eurasian Basin is generally accompanied by net PV outflow. On the other hand, for the Amerasian Basin none of the experiments gives indications for a balance of PV inflow and dissipation. Instead, the tendency of PV and vertical PV fluxes has to balance the dissipation in the Amerasian Basin.

[43] The model drift of the AOMIP experiments leads to a vanishing feeding of AW from the Barents Sea shelf, concluded to be the major source of high PV water for the Eurasian Basin. This, and the likely less realistic hydrography as a consequence of the drift, leads us to analyse two additional experiments. They are based on the AWI model, however, using surface salinity restoring over the entire period of integration. Experiment AWI_NCEP (1948-2004) is driven by NCEP atmospheric reanalysis, initialized from a spin-up experiment (AWI_CLIMAT) that is driven by an ERA15-derived climatology.

[44] In these experiments net PV flux happens to occur into the Eurasian Basin over the entire experimental period, again dominated by the flux via St. Anna Trough. Vanishingly small tendency of PV and a cyclonic flow in the Eurasian Basin support the principal balance of PV inflow and dissipation for this basin.

[45] For the Eurasian Basin the topostrophy is largely controlled by net PV inflows on long timescales $(>5-6$ years). This PV inflow is associated with a large scale SLP depression encompassing the entire Eurasian Arctic and the Nordic Seas, suggesting a link with the intensity of south westerly airflows in the area. A decomposition of PV flux into contribution of velocity changes and PV changes decovers the latter as the more important factor determining the PV inflow intensity. The Barents Sea, which is known to be a significant area of dense water production [Schauer et al., 2002], is the source region for the high PV influx via St. Anna Trough. Owing to dense water formation in winter and restratification in summer, strong stratification occurs in the midrange density classes that later feed into the AWL as high PV flow. We find anomalously large buoyancy losses in the eastern Barents Sea and subsequent anomalously strong stratification in the AWL density range preceding periods of high PV flow into the Eurasian Basin via St. Anna Trough. We submit changes in the ice cover of the Barents Sea as an important factor for the buoyancy loss, linking the PV production and inflow with the large scale SLP field.

[46] The existence of an anticyclonic flow in the Amerasian Basin in the AWI_CLIMAT experiment supports the result from the AOMIP experiments that high net PV inflow into the Arctic Ocean is not sufficient to determine the rotation of all subbasins. We argue that the local wind field over the Amerasian Basin is responsible for the anticyclonic flow in the Amerasian Basin. In AWI CLIMAT the atmospheric climatology persistently forces a constantly strong anticyclonic Beaufort Gyre at the surface. The hydrography adjusts to this permanent force. Consequently, the Beaufort Gyre is very deep and the upper density interval of the AWL responds with large depression in the center of the gyre. The AWL flows with the same sense of rotation, no counter current can establish.

[47] In the more realistic, NCEP-driven experiment, the local wind field is a major driving force for the Amerasian Basin flow at the surface and at AWL depths, too. Since the intensity of the high pressure system over the Arctic is variable on a timescale of several years [e.g., Proshutinsky and Johnson, 1997], there is not enough time for the hydrography to adjust to equilibrium. However, the local wind forcing modifies the intensity of the AWL by influencing the halocline depth, which exhibits a larger Beaufort Gyre and more intense gradients for years in which the integrated curl of the upper ocean velocities in the deep basins is strongly anticyclonic. We suppose that in the PV balance, the surface influence acts via vertical fluxes of PV, e.g. by interfacial stress and stretching as a consequence of Ekman pumping.

[48] Local as well as large-scale wind fields are connected to the inflow of PV from the Barents Sea and the topostrophy in the Amerasian Basin, as suggested by regression on the northern hemispheric SLP. The Amerasian Basin topostrophy is associated with anomalously low pressure over the Canadian Basin and a high pressure anomaly over the Bering Sea. Consistently, the correlation of topostrophy in the Amerasian Basin with the pressure difference between the Canadian Basin center and the Bering Sea is high throughout the entire experimental period.

[49] While we understand the formation process of the high PV water and its consequences for the AWL flow based on the presented results, we are not able at present to fully describe the physical mechanisms acting during the conversion of the strongly stratified high PV shelf water to the thick AWL in the basins. We suspect that the transformation involves nonlinear dynamics, intense stretching [Schauer et al., 1997], and cross-isopycnal exchange. The same hold for the details of the physical processes linking the wind fields over the Amerasian Basin with the vertical PV fluxes which influence the AWL. In numerical experiments the sense and intensity of AWL circulation is also influenced by the parameterization chosen to represent physical processes. Explicitly the influence of vertical mixing intensity on the flow of Atlantic Water in the Arctic Ocean has been investigated by Zhang and Steele [2007] based on one of the AOMIP models also used here (UW).

[50] In summary, for the Eurasian Basin the results of the AWI and the AOMIP-subset experiments are consistent with the notion of Yang [2005] that the lateral PV input is a key ingredient for the existence of cyclonic flow in the AWL. We suggest that with no or negative net lateral PV fluxes, models are more prone to produce anticyclonic flow in the Eurasian Basin AWL. Since the PV flux through St. Anna Trough is the dominant source, we claim deep water formation and restratification on the Barents Sea shelf to have a big influence on the intensity and direction of Atlantic Water flow. This does not imply, however, that the 
lateral PV flux is the only ingredient to determine the flow direction and intensity, especially on interannual timescale. For the Amerasian Basin there is no such balance as supposed by Yang [2005]. Instead we have found the local wind fields as a very influential factor for this basin.

[51] It has been our aim to add to the knowledge on the mechanisms responsible for the AWL flow in the Arctic Ocean by investigating aspects of its PV balance. The fact that we found a balance of lateral PV inflow from the Barents Sea and dissipation by cyclonic boundary currents in the Eurasian Basin does not imply that other factors, external or internal, do not play a role for the Atlantic Water in the Arctic Ocean. For example, the inflow through Fram Strait undoubtedly provides the largest heat and salt input to the Arctic Ocean at mid depth, and thus has an influence on the state of the AWL as a temporal storage for heat and salt. This is true despite the small role of the Fram Strait inflow for the lateral PV fluxes. We also do not answer the question here, whether the existence of AW inflow via the Fram Strait and the Barents Sea at all is rather due to local Arctic processes or due to external forces. On the other hand, we found the interpretation of PV balances a helpful tool in understanding mechanisms closely linked to the intensity and the sense of AW flow in different Arctic models. While in the Eurasian Basin the lateral PV inflow certainly sets the scene for "what is to be balanced", in the Amerasian Basin, which does not receive direct inflow of highly stratified water into the AWL, local wind influence seems much more significant, These are exerted e.g. via the upper layer flow and deformation of the halocline. Whether a complete decoupling of the Amerasian and Eurasian basin circulation or long periods of anticyclonic flow in the AWL at all occur in reality is an open question. It may be possible if an anomalously high pressure situation in the central Arctic lasts long enough for the hydrography to develop a deep, strong Beaufort Gyre that is able to suppress the counter current in the AWL below. Despite the value of a posteriori analyses of model experiments these have their limits, specifically in the determination of causal relationships. We submit that for further progress in the separation of the competing influences which determine AW flow dedicated sensitivity experiments with full-fledged GCMs will have to be performed.

[52] Acknowledgments. The first two authors have contributed equally to the publication. This research is supported by the National Science Foundation Office of Polar Programs under cooperative agreements OPP-0002239 and OPP-0327664 with the International Arctic Research Center, University of Alaska Fairbanks. R.G. also wants to acknowledge the support by the Deutsche Forschungsgemeinschaft via the SFB 512 E.H.'s work was supported by the Climate Change Prediction Program of the Department of Energy's Office of Biological and Environmental Research. She especially thanks John Drake and the Center for Computational Sciences at Oak Ridge National Laboratory for extensive use of their Cray X1. The development of the UW model is also supported by NSF (grants OPP-0240916; OPP-0229429) and NASA (grants NNG04GB03G; NNG04GH52G). M.K. and F.K. also would like to express thanks for support from the European Comission under the FP6 project DAMOCLES.

\section{References}

Aagaard, K. (1989), A synthesis of the Arctic Ocean circulation, Rapp. P.-V. Reun. Cons. Int. Explor. Mer., 188, 11-22.

Gerdes, R., and U. Schauer (1997), Large-scale circulation and water mass distribution in the Arctic Ocean from model results and observations, J. Geophys. Res., 102(C4), 8467-8483.
Gerdes, R., M. J. Karcher, F. Kauker, and U. Schauer (2003), Causes and development of repeated Arctic Ocean warming events, Geophys. Res. Lett., 30(19), 1980, doi:10.1029/2003GL018080.

Gerdes, R., J. Hurka, M. Karcher, F. Kauker, and C. Koeberle (2005), Simulated history of convection in the Greenland and Labrador seas 1948-2001, in Climate Variability of the Nordic Seas, pp. 221-238, Bjerknes Cent. for Clim. Res., Bergen, Norway.

Häkkinen, S., and G. L. Mellor (1992), Modeling the seasonal variability of the coupled Arctic ice-ocean system, J. Geophys. Res., 97, 20,28520,304 .

Häkkinen, S., F. Dupont, M. Karcher, F. Kauker, D. Worthen, and J. Zhang (2007), Model simulation of Greenland Sea upper-ocean variability, J. Geophys. Res., doi:10.1029/2006JC003687, in press.

Holland, D. M., L. A. Mysak, and J. M. Oberhuber (1996), An investigation of the general circulation of the Arctic Ocean using an isopycnal model, Tellus, Ser. A, 48, 138-157.

Holloway, G., et al. (2007), Water properties and circulation in Arctic Ocean models, J. Geophys. Res., 112, C04S03, doi:10.1029/ 2006JC003642.

Hunke, E. C., and M. Holland (2007), Global atmospheric forcing data for Arctic ice-ocean modeling, J. Geophys. Res., 112, C04S14, doi:10.1029/ 2006JC003640

Hurrell, J. W. (1995), Decadal trends in the North Atlantic Oscillation: Regional temperatures and precipitation, Science, 269, 676-679.

Karcher, M. J., and J. M. Oberhuber (2002), Pathways and modification of the upper and intermediate waters of the Arctic Ocean, J. Geophys. Res., 107(C6), 3049, doi:10.1029/2000JC000530.

Karcher, M. J., R. Gerdes, F. Kauker, and C. Köberle (2003a), Arctic warming: Evolution and spreading of the 1990s warm event in the Nordic Seas and the Arctic Ocean, J. Geophys. Res., 108(C2), 3034 doi:10.1029/2001JC001265.

Karcher, M. J., R. Gerdes, F. Kauker, C. Koeberle, and U. Schauer (2003b), Transformation of Atlantic Water in the Barents Sea between 1948 and 2002, paper presented at Seventh Conference on Polar Meteorology and Oceanography and Joint Symposium on High-Latitude Climate Variations, Extended Abstract [CD-ROM], Hyannis, Mass., 12-16 May.

Karcher, M., R. Gerdes, F. Kauker, C. Koeberle, and I. Yashayev (2005), Arctic Ocean change heralds North Atlantic freshening, Geophys. Res. Lett., 32, L21606, doi:10.1029/2005GL023861.

Kauker, F., R. Gerdes, M. J. Karcher, C. Köberle, and J. L. Lieser (2003), Variability of Northern Hemisphere sea ice: A combined analysis of model results and observations from 1978 to 2001, J. Geophys. Res., 108(C6), 3182, doi:10.1029/2002JC001573.

Kauker, F., R. Gerdes, M. Karcher, and C. Köberle (2005), Impact of North Atlantic Current changes on the Nordic Seas and the Arctic Ocean, J. Geophys. Res., 110, C12002, doi:10.1029/2004JC002624.

Levitus, S., R. Burgett, and T. Boyer (1994), World Ocean Atlas 1994, vol. 3 , Salinity, NOAA Atlas NESDIS 3, U. S. Dep. of Commer., Washington, D. C. Mauritzen, C. (1996), Production of dense overflow waters feeding the North Atlantic across the Greenland-Scotland Ridge. Part 1: Evidence for a revised circulation scheme, Deep Sea Res., Part I, 43, 769-806.

Nazarenko, L., G. Holloway, and N. Tausnev (1998), Dynamics of transport of Atlantic signature in the Arctic Ocean, J. Geophys. Res., 103, 31,00331,015 .

NSIDC Environmental Working Group (1997), Joint U.S. Russian Atlas of the Arctic Ocean: Oceanography Atlas for the Winter Period [CD-ROM], Univ. of Colo., Boulder.

Proshutinsky, A. Y., and M. A. Johnson (1997), Two circulation regimes of the wind-driven Arctic Ocean, J. Geophys. Res., 102, 12,493-12,514

Proshutinsky, A., et al. (2005), Arctic Ocean Study - Synthesis of model results and observations, Eos Trans. $A G U, 86(40), 368$.

Röske, F. (2001), An atlas of surface fluxes based on the ECMWF re-analysis - a climatological data set to force global ocean general circulation models, MPI Rep. 323, Max-Planck-Inst. für Meteorol., Hamburg, Germany.

Rudels, B., E. P. Jones, L. G. Anderson, and G. Kattner (1994), On the intermediate depth waters of the Arctic Ocean, in The Polar Oceans and Their Role in Shaping the Global Environment, Geophys. Monogr. Ser. vol. 85, edited by O. M. Johannessen, R. D. Muench, and J. E. Overland, pp. 33-46, AGU, Washington, D. C.

Rudels, B., P. Eriksson, H. Grönvall, R. Hietala, and J. Launiainen (1999), Hydrographic observations in Denmark Strait in fall 1997, and their implications for the entrainment into the overflow plume, Geophys. Res. Lett., 26(9), 1325-1328.

Schauer, U., R. D. Muench, B. Rudels, and L. Timokhov (1997), Impact of Eastern Arctic Shelf waters on the Nansen Basin intermediate layers, J. Geophys. Res., 102, 3371-3382.

Schauer, U., H. Loeng, B. Rudels, B. Ozhigin, and V. K. Dieck (2002), Atlantic water flow through the Barents and Kara Seas, Deep Sea Res., Part I, 49(12), 2281-2298. 
Schlosser, P., J. H. Swift, D. Lewis, and S. L. Pfirman (1995), The role of the large-scale Arctic Ocean circulation in the transport of contaminants, Deep Sea Res., Part II, 42, 1341-1367.

Smethie, W. M., Jr., P. Schlosser, G. Boenisch, and T. S. Hopkins (2000), Renewal and circulation of intermediate waters in the Canadian Basin, observed on the SCICEX 96 cruise, J. Geophys. Res., $105,1105-1121$

Smith, J. N., K. M. Ellis, and T. Boyd (1999), Circulation features in the western Arctic Ocean revealed by nuclear fuel tracers from scientific ice expeditions 1995 and 1996, J. Geophys. Res., 104, 29,663-29,677.

Steele, M., R. Morley, and W. Ermold (2001), PHC: A global ocean hydrography with a high quality Arctic Ocean, J. Clim., 14, 2079-2087.

Steiner, N., et al. (2004), Comparing modeled streamfunction, heat and freshwater content in the Arctic Ocean, Ocean Modell., 3-4, 265-284.

Swift, J. H., E. P. Jones, K. Aagaard, E. C. Carmack, M. Hingston, R. W. Macdonald, F. A. McLaughlin, and R. G. Perkin (1996), Waters of the Makarov and Canada basins, Deep Sea Res., Part II, 44, 3371-3382.

Uotila, P., et al. (2005), An energy-diagnostics intercomparison of coupled ice-ocean Arctic models, Ocean Modell., doi:10.1016/j.ocemod. 2004.11.003. van Loon, H., and J. C. Rodgers (1978), The seasaw in winter temperatures between Greenland and northern Europe. Part I: General description, Mon. Weather Rev., 106, 296-310.

Yang, J. (2005), The Arctic and Subarctic ocean flux of potential vorticity and the Arctic Ocean circulation, J. Phys. Oceanogr., 35(12), $2387-$ 2407, doi:10.1175/JPO2819.1.

Yang, J., and J. F. Price (2000), Water-mass formation and potential vorticity balance in an abyssal ocean circulation, J. Mar. Res., 58, 789-808. Zhang, J., and M. Steele (2007), Effect of vertical mixing on the Atlantic Water layer circulation in the Arctic Ocean, J. Geophys. Res., 112, C04S04, doi:10.1029/2006JC003732.

R. Gerdes, M. Karcher, and F. Kauker, Alfred Wegener Institute for Polar and Marine Research, D-27515 Bremerhaven, Germany. (mkarcher@ awi-bremerhaven.de)

E. Hunke, Los Alamos National Laboratory, Los Alamos, NM 87545 , U.S.A.

J. Zhang, Polar Science Center, Applied Physics Laboratory, University of Washington, Seattle, WA 98105, U.S.A. 